\title{
Gender differences in attachment anxiety and avoidance and their association with psychotherapy use - Examining students from a German university
}

Weber, R. ${ }^{1}$, Eggenberger, L. ${ }^{2}$, Stosch, C. ${ }^{3}$, Walther, A. ${ }^{2, *}$

\footnotetext{
${ }^{1}$ University of Cologne, Faculty of Medicine and University Hospital Cologne, Clinic and Polyclinic for Psychosomatics and Psychotherapy, Germany

${ }^{2}$ Clinical Psychology and Psychotherapy, University of Zurich, Zurich, Switzerland

${ }^{3}$ Student Deans Office, Medical Faculty, University of Cologne, Germany

${ }^{*}$ Correspondence
}

Running head: Gender differences in attachment and psychotherapy use

Words (Text): 5’325

Words (Abstract): 302

References: 68

Tables: 1

Figures: 5

Correspondence to: Dr. Andreas Walther, Binzmühlestrasse 14, 8050, Zürich; Clinical Psychology and Psychotherapy, University of Zurich, Zurich, Switzerland a.walther@psychologie.uzh.ch 


\section{Abstract}

Background: Attachment anxiety and avoidance have been insufficiently studied in relation to psychotherapy use. Attachment theory, specifically attachment anxiety and avoidance, might explain gender differences in psychotherapy use, which is generally lower in those identifying as male. In addition, university students are a particularly vulnerable group for mental health problems, and understanding psychotherapy use, especially among mentally distressed male students, is pivotal.

Methods: A total of 44,299 students from a German university were invited to participate in an online survey on the topic of "studying with mental stress", and 4,894 completed the survey (adjusted response rate of $11.04 \%$ ). The students answered questions regarding psychotherapy use, and they completed the Patient Health Questionnaire (PHQ-D) identifying syndromes of depression, anxiety, alcohol use, somatoform and eating disorders. In addition, the Experiences in Close Relationships - Revised (ECR-RD12) questionnaire, was used to measure attachment anxiety and avoidance.

Results: Significant gender differences for attachment anxiety and avoidance emerged showing higher attachment anxiety in female students and higher attachment avoidance in male students. In addition, male students used psychotherapy significantly less than female students, and they also reported less intention to use psychotherapy in the near future. Male students did not differ from female students with regard to mental distress. When exploring regressions to predict psychotherapy use, male students' attachment anxiety and avoidance predicted use. For female students, only attachment anxiety emerged as a significant predictor. However, when correcting for multiple testing, only attachment anxiety remained a significant predictor of psychotherapy use for male and female students.

Conclusion: Attachment anxiety is positively associated with psychotherapy use and lower attachment anxiety in men may partially explain lower psychotherapy use in male university students. Lower attachment anxiety in male students emerges as a relevant factor explaining lower psychotherapy use in males, which is not balanced by higher attachment avoidance in males.

Key words: psychotherapy use, attachment, attachment anxiety, attachment avoidance, gender differences, depression, somatoform disorder 


\section{Introduction}

Men and women differ with regard to the prevalence of several mental disorders with women showing higher rates in depressive disorders, somatoform disorders, anxiety disorders and eating disorders (Bandelow \& Michaelis, 2015; De Waal et al., 2004; Galmiche et al., 2019; Hasin et al., 2018; Jacobi et al., 2014; Salk et al., 2017), while men show higher rates in substance use disorders and especially in alcohol use disorders (Grant et al., 2015, 2016). Although, overall men and women experience similar levels of psychological distress, men use psychotherapy about 30\% less than women (Brandstetter et al., 2017; Eggenberger et al., 2021; Rommel et al., 2018; Walther et al., 2021; Walther \& Seidler, 2020). Whether this pattern differs with regard to differing psychological syndromes is, however, insufficiently studied.

A person's attachment dimension has further been suggested to influence one's decision to take on psychotherapy or not when facing psychological distress (Dozier, 1990). Furthermore, a commonly discussed reason for lower psychotherapy use in men as compared to women is the endorsement of traditional masculinity ideology with the two main foci of "be in control" and "be unlike women" (Eggenberger et al., 2021; Levant et al., 2016; Seidler et al., 2016; A Walther et al., 2021; Wong et al., 2017). It has been shown in several studies that the endorsement of traditional masculinity ideology is significantly associated with attachment orientation suggesting a shared potential to explain psychotherapy use (Calzo, 2010; Fitzpatrick, 2016; Saldubehere, 2019; Smiler \& Heasley, 2016). Regardless of one's endorsement of traditional masculinity ideology, a person's attachment orientation appears to be critical to the engagement in psychotherapy, as it has a central role in approaching and acting in social relationships and self-disclosure (Dozier, 1990). Attachment orientation is operationalized using a two-dimensional conceptualization namely of attachment anxiety and attachment avoidance (Bartholomew et al., 2001; Mikulincer \& Shaver, 2005). Anxiously attached individuals generally have a negative view of the self, tend to be dependent on others and are hypervigilant to social and emotional cues from others (Fraley et al., 2006; Gillath et al., 2005; Richards \& Schat, 2011). By contrast, individuals exhibiting an avoidant attachment orientation generally perceive others as unavailable, unresponsive, or punitive (Mikulincer \& Shaver, 2005; Richards \& Schat, 2011). Thus, individuals with an avoidant attachment orientation engage more in deactivation strategies by denying the importance of relationships and avoiding emotional intimacy (Mikulincer et al., 2003). Therefore, individuals 
exhibiting low attachment anxiety and avoidance generally view themselves as valuable and perceive others as trustworthy (Mikulincer \& Shaver, 2005; Richards \& Schat, 2011).

Many individuals who seek psychotherapeutic services exhibit anxious or avoidant attachment orientations, while in psychotherapy, the client-therapist relationship has many characteristics of an attachment relationship (Slade \& Holmes, 2019). The therapist is supposed to serves as a secure base, acting as a potential agent of change to support the client in developing his intimate connections, social relationships, and autonomous exploration. A secure attachment organization with the therapist was shown to predict positive working alliance, more compliance and greater engagement in therapy (Diener \& Monroe, 2011; Dozier, 1990; Mikulincer et al., 2013). By contrast, stronger attachment avoidance was associated with rejection of treatment providers, reduced self-disclosure, and poorer use of treatment (Dozier, 1990), which are rather typical issues in male clients (Seidler et al., 2021; Walther \& Seidler, 2020), highlighting the question whether gender differences in attachment anxiety and avoidance are associated with psychotherapy use.

A significant problem in research on attachment theory is rooted in the fact that different research traditions, each with different questions and measurement methods, lead to different results. For example, the categorical approach of attachment research can be attributed more to a developmental psychological research approach in which observer assessment procedures such as an interview or projective procedures predominate. The dimensional research approach can instead be attributed to the field of personality and social psychology, in which questionnaires (self-assessment procedures) represent the method of choice (Crowell et al., 2016; Kirchmann \& Strauß, 2008). This is also evident in the question of gender differences. Gender differences in attachment organization have been reported early on with men being overrepresented in the attachment avoidant category as compared to women when using the adult attachment interview (AAI) (Dozier, 1990). Yet, a meta-analysis examining gender differences in the AAl did not identify consistent gender differences in attachment representations (Bakermans-Kranenburg \& van IJzendoorn, 2009). This is contrasted by consistently reported gender differences when using a dimensional approach with self-report questionnaires to assess attachment dimensions, (Del Giudice, 2009; Del Giudice \& Belsky, 2010; Petrowski et al., 2020). A meta-analysis examining attachment dimensions measured with psychometric scales (Experience in Close Relationships [ECR]; Experience in Close Relationships - Revised [ECR-R]; Adult Attachment Questionnaire) reveals 
that women exhibit higher attachment anxiety, while men exhibit higher attachment avoidance (del Giudice, 2011). This further led to the claim to consistently integrate gender differences between men and women in attachment research (Del Giudice, 2019; Duschinsky et al., 2021).

Potential gender differences in attachment organization in university students are still insufficiently examined and might help to further explain gender differences in psychotherapy use in this population and ultimately inform tailored mental health support systems for male and female students. Till date, no study has investigated whether men and women differ in their choice to take on psychotherapy depending on specific psychological syndromes and their level in attachment anxiety or avoidance. Based on the outlined literature on gender differences in psychotherapy use and attachment organization, we hypothesize that individuals with higher attachment anxiety having a more negative view of the self and being more dependent on others will use psychotherapy more than individuals with low attachment anxiety. For attachment avoidance, the empirical basis leads less unambiguously to distinct hypotheses. Here, two scenarios would be possible. On the one hand, for individuals with high attachment avoidance, who generally perceive others as unavailable, unresponsive, or punitive and deny the importance of relationship and avoid emotional closeness, it can be assumed that these individuals are reluctant to engage in psychotherapy. However, on the other hand, it can be assumed that with high attachment avoidance, major interpersonal problems arise in the life course and that these persons then finally make use of psychotherapy. Therefore, it can be assumed that attachment avoidance is also positively associated with the use of psychotherapy, but that this is less pronounced than in the case of attachment anxiety. Since women are expected to have higher attachment anxiety and men higher attachment avoidance, these gender differences in attachment organization may partly explain gender differences in psychotherapy use.

\section{Methods}

\section{Sample and procedure}

The study was conducted at the University of Cologne in the winter semester 2014/2015 (December 2014 to February 2015) as part of an online survey (KUmBel; Kölner Umfrage bei Studierenden zu psychischen Belastungen). Description of the study sample and survey procedure are reported in detail elsewhere (Weber et al., 2020). The University of Cologne is 
divided into six faculties: the Faculty of Economics and Social Sciences, the Faculty of Law, the Faculty of Medicine, the Faculty of Philosophy, the Faculty of Mathematics and Natural Sciences, and the Faculty of Human Sciences. Of the 49,772 students enrolled in the winter semester 2014/2015, a total of 44'299 students at the University of Cologne were invited to participate in the online survey via the overall e-mail distribution list.

With the invitation email, students received a link to an online platform (Leiner, 2019), where the survey could be completed. After four weeks, a reminder email was sent out to potential participants. For survey completion, participants needed about 20-30min. The Ethics Committee of the Medical Faculty of the University of Cologne gave its positive vote after extensive consultation on the issues relevant to data protection.

\section{Measures}

Participants were asked several sociodemographic questions (e.g. age, gender, nationality, previous vocational training) and course-related questions (e.g. course of study, subject semesters, ways of financing studies, thoughts of dropping out) were collected. Gender was assessed using a binary response option, where students could indicate to self-identify as "woman" or "man". In addition, information on current and intended psychotherapy use for mental health problems was obtained. Regarding current psychotherapy use, students were asked directly whether they were currently receiving psychotherapy ("Yes"/"No"), while the question about intention to start psychotherapy asked students whether they had thought about receiving psychotherapy ("Yes"/"No"). In a previous study with German-speaking students, the item on current psychotherapy use showed high reliability (Cohen's kappa $\mathrm{k}=$ .92) over a one-month period, as well as significant convergent validity with depression symptoms (PHQ-9; point biserial correlation coefficient $r_{\mathrm{pb}}=.18, p<.001$ ) and anxiety symptoms (GAD-7; $r_{\mathrm{pb}}=.17, p<.001$ ) (Eggenberger, 2021). On the other hand, the same study supported the discriminant validity of this item with significant negative correlations between current psychotherapy use and self-esteem $\left(r_{\mathrm{pb}}=-.19, p<.001\right)$, optimism $\left(r_{\mathrm{pb}}=-.10, p=.009\right)$, and resilience $\left(r_{\mathrm{pb}}=-.11, p=.008\right)$ (Eggenberger, 2021). In the present study, convergent validity of the two items was further supported by a significant positive correlation between current psychotherapy use and suicidal ideation (Pearson's phi coefficient $r_{\phi}=.15, p<.001$ ) as well as between the intention to start psychotherapy and suicidal ideation $\left(r_{\phi}=.30, p<\right.$ $.001)$. 
The mental distress of the students was assessed with the Patient Health Questionnaire (PHQ-D; Löwe et al., 2002), the German version of the Patient Health Questionnaire (PHQ; Spitzer et al., 1999). Designed as a self-report instrument, the PHQ-D is a standard instrument for screening the most common mental disorders. In addition to psychosocial functioning and eight common psychosocial stressors, the complete version (78 items) covers a total of eight psychiatric disorders according to DSM-IV criteria. A previous study reported an internal consistency for the depression module of $\alpha=0.88$ and for the somatization module of $\alpha=0.79$ (Löwe et al., 2004). In the present study comparable values for the internal consistency were identified for the depression module of $\alpha=0.86$ and for the somatization module of $\alpha=0.76$.

We used the Experiences in Close Relationship - Revised (ECR-RD12) to measure attachment anxiety and attachment avoidance (Ehrenthal et al., 2008; Fraley et al., 2011). The 12-item scale measures the two dimensions of attachment: anxiety (6 items) and avoidance (6 items). Sample items are "I worry quite a bit about losing connection with other people" (anxiety) and "I don't feel comfortable opening up to other people" (avoidance). Responses were given on a 7-point Likert scale from "strongly disagree" to "strongly agree.". Previously, high internal consistency was reported for the German translation of the ECR-R with Cronbach's $\alpha=0.91$ and 0.92 for the two scales. In the present study, the two scales revealed an internal consistency of $\alpha=0.82$ for attachment anxiety and for attachment avoidance of $\alpha$ $=0.78$.

\section{Statistical analysis}

The statistical analysis was conducted in the R software environment (R Core Team, 2020), including the additional R-packages "psych" (Revelle, 2020; calculation of internal consistencies), "car" (Fox \& Sanford, 2019; calculation of variance inflation factors), "rcompanion" (Mangiafico, 2021; maximum likelihood estimates of pseudo $R^{2}$ and $p$-values in the logistic regression setting), and "ggplot2" (Wickham, 2016; visualizations). The analysis consisted of the four steps described in the following, with the covariates age and nationality included in all calculations. To test significance of the results, an initial alpha-level of $\alpha=0.05$ was used for each step. Subsequently, the results were checked for robustness using the Holm-Bonferroni correction for multiple testing. Furthermore, for all calculations where the ECR-RD12 was involved a slightly reduced sample of $N=4705$ was used due to some missing values. 
In a first step, the sample characteristics were analyzed by calculating mean scores for the continuous variables and relative percentages for the categorical variables, once for the total sample and once for men and women separately. In a second step, group differences between men and women in regards to attachment anxiety and attachment avoidance, screened psychiatric syndromes, and psychotherapy use were analyzed using two-sided $t$ tests for the continuous variables and two-sided Wald-tests for the categorical variables. In a third step, binary logistic regression models were fitted to assess the predictive value of attachment orientation for the likelihood to use or the intention to start psychotherapy, once in the total sample, once for men and women separately, and once for all individual subgroups consisting of participants screened positive for a psychiatric syndrome. In a fourth and last step, moderation analyses were conducted using Hayes' (2013) regression-based approach to test for possible moderating effects of attachment orientation on the association between the likelihood to use or the intention to start psychotherapy and the positive screening for different psychiatric syndromes.

Assumptions for the previously described analyses and statistical tests were assessed by using Levene's median-based test for equal variances (Brown \& Forsythe, 1974; testing homoscedasticity for the $t$-tests), Cook's distance (Cook, 1977; detecting influential points in the logistic regression models), and the generalized variance inflation factor proposed by Fox and Monette (1992; detecting collinearity of predictor variables in the logistic regression models).

\section{Results}

\section{Sample characteristics}

As presented in Table 1, the total sample of the study consisted of 4894 participants, of which 1207 were men (24.7\%) and 3687 were women (75.3\%). The vast majority were of German nationality $(94.7 \%)$. About one-fifth of the students had previously completed another degree program (19.4\%), and while about one-quarter had previously dropped out of another degree program (24.2\%), nearly half the students were currently thinking about dropping out of their current program (45.6\%). The majority of participants received financial support either from their relatives (70.5\%) or through an additional job alongside their studies (67.8\%). Though most of the students previously had contact with a counseling service $(71.2 \%)$ and about onequarter previously used psychotherapeutic treatment (26.0\%), fewer than every tenth student was currently using psychotherapy (8.7\%). Nonetheless, about every fourth student expressed 
the intention to use psychotherapy in the future (28.4\%). Furthermore, about one-fifth of the students previously required medical care $(21.4 \%)$ and a small minority was currently undergoing medical treatment (6.9\%). Additionally, about one-tenth of the students reported to suffer from a physical impairment $(9.4 \%)$, about one-twentieth was currently taking psychiatric medication (6.0\%), and a minority previously experienced physical or sexual abuse (3.5\%).

Regarding psychological distress, more than half the students screened positive for at least one psychiatric syndrome (58.4\%). Most students screened positive for a depressive syndrome (34.9\%), followed by a somatoform syndrome (23.6\%) and an alcohol use syndrome (19.1\%). Roughly the same number of students suffered from an anxiety syndrome (12.5\%) as suffered from an eating disorder syndrome (11.8\%).

\section{Group comparisons}

As presented in Figure 1 and Table 1, women had a significantly higher mean score for attachment anxiety compared to men, while men had a significantly higher mean score for attachment avoidance as compared to women. These differences also remained significant after applying the Holm-Bonferroni correction for multiple testing.

In terms of positive psychiatric syndrome screenings with the PHQ-D (Figure 2, Table 1), significantly more women than men were screened positive for any depressive syndrome (minor and/or major depression), any anxiety syndrome (panic and/or generalized anxiety), and generalized anxiety syndrome. And while significantly more men than women were screened positive for an alcohol use syndrome, significantly more women than men were screened positive for a somatoform syndrome and any eating disorder syndrome (bulimia nervosa and/or binge eating). However, after applying the Holm-Bonferroni correction for multiple testing, the gender differences for any depressive syndrome and any eating disorder syndrome did no longer reach statistical significance. Regarding psychotherapy use, men were about $26.9 \%$ less likely to use psychotherapy compared to women and men were also about 23.8\% less likely to have the intention to start psychotherapy in the future compared to women. These differences remained significant after a Holm-Bonferroni correction.

Analyzing individual subgroups screened positive for a psychiatric syndrome in regards to gender differences in current psychotherapy use (Figure $3 \mathrm{~A}$ ) it emerged that men screened positive for at least one psychiatric syndrome (9.0\%) were significantly less likely to currently 
use psychotherapy compared to women screened positive for at least one psychiatric syndrome $\left(11.5 \% ; z[2851]=-2.33, p=.020\right.$, Nagelkerke $\left.R^{2}=.022, \mathrm{AIC}=1947.9\right)$. However, this result was no longer significant after applying the Holm-Bonferroni correction. Examining the same subgroups for gender differences in the intention to start psychotherapy (Figure 3B) revealed that significantly fewer men screened positive for any syndrome $(32.0 \%)$ were intending to start psychotherapy in the future compared to women screened positive for any syndrome (39.9\%; $z$ [3777] $=-3.72, p=<.001$, Nagelkerke $R^{2}=.008$, AIC = 3787). Similarly, fewer men screened positive for major depression (48.3\%), alcohol use syndrome (27.6\%), and any eating disorder syndrome (28.5\%) were intending to start psychotherapeutic treatment in the future compared to women screened positive for major depression (57.7\%), alcohol use syndrome (36.0\%), and any eating disorder syndrome (47.8\%). (major depression: $z$ [1002] = 2.42, $p=.015$, Nagelkerke $R^{2}=.010$, AIC = 1385.9; alcohol use syndrome: $z[929]=-2.77, p=$ .006, Nagelkerke $R^{2}=.014$, AIC $=1185$; any eating syndrome: $z[751]=-2.34, p=.019$, Nagelkerke $\left.R^{2}=.023, \mathrm{AIC}=763.3\right)$. After correcting these findings for multiple testing, the only difference that remained significant was the gender difference in the subgroup screened positive for any psychiatric syndrome.

\section{Logistic regressions}

Fitting binary logistic regression models to predict current psychotherapy use based on attachment orientation in different subgroups (Figure 4, S-Table 1), showed that higher attachment anxiety predicted higher odds to currently use psychotherapy in the total sample (Figure 4A), as well as in all other examined subgroups (Figures 4B - 4I). These results remained significant even after applying a Holm-Bonferroni correction. On the other hand, higher attachment avoidance did predict higher odds for current psychotherapy use in male students (Figure 4B) and in students screened positive for alcohol use disorder (Figure 4G). However, these results for attachment avoidance became nonsignificant after applying the HolmBonferroni correction for multiple testing. Similarly, attachment avoidance did not have any predictive value for current psychotherapy use for the total sample (Figure 4A), for female students (Figure $4 C$ ), or any of the other subgroups screened positive for a psychiatric syndrome (Figures 4D - 4F, 4H, 4I).

Examining the same subgroups but predicting the intention to start psychotherapy as an outcome based on attachment orientation (Figure 5, S-Table 2), showed that higher 
attachment anxiety was a significant predictor for higher odds of intending to start psychotherapy in the total sample (Figure 5A), as well as in all other subgroups that were analyzed (Figure 5A-5I). Again, these results remained significant after correcting for multiple testing. Similarly, higher attachment avoidance would predict higher odds of intending to start psychotherapy in the total sample (Figure 5A) and in all subgroups except in students screened positive for any eating disorder syndrome (Figure 5I). Yet, after applying the Holm-Bonferroni correction, attachment avoidance was only significantly associated with the intention to start psychotherapy in the total sample (Figure 5A), in female students (Figure 5B), in students screened positive for any psychiatric syndrome (Figure 5D), and in students screened positive for any depressive syndrome (Figure 5E). Further analyses, where the positively-screened subgroups were additionally separated by gender, can be found in the supplementary (SFigure 1-S-Figure 4).

As purely exploratory analyses reported in the Supplementary, moderation analyses were carried out investigating possible moderating effects of attachment orientation on the association between individual psychiatric syndromes and psychotherapy use (see S-Figure 5).

\section{Discussion}

\section{Summary of results}

In the present study, a significant gender difference was observed in the two attachment dimensions of attachment anxiety and attachment avoidance. Male university students showed significantly lower attachment anxiety and significantly higher attachment avoidance. Furthermore, male students reported to engage significantly less in psychotherapy as compared to female students and also reported lower intentions to use psychotherapy in the near future as female students. Male and female students did not differ in general psychological distress, while male students tend to show lower rates in positive syndrome screenings with the PHQ-D for all syndromes except for the alcohol use disorder syndrome, where for more male students than female students a positive screening was observed. In male students, current psychotherapy use was predicted by attachment anxiety and avoidance, while only the association between attachment anxiety and psychotherapy use survived correction for multiple testing. In female students only attachment anxiety emerged as a significant predictor of psychotherapy use. In exploratory analyses (see Supplementary), attachment anxiety emerged as a significant moderator of the association between suffering 
from a depressive or somatoform syndrome and current psychotherapy use in female, but not male, students, with higher attachment anxiety leading to increased psychotherapy use. However, moderation effects did not remain significant after correction for multiple testing.

\section{Integration of findings}

As widely established (Rosenfield, 1999; Rosenfield \& Smith, 2010; Vos et al., 2017), also in the present study men and women and more precisely, male students and female students, did not differ in overall psychological distress as measured by the PHQ-D any syndrome. However, as presented in Figure 2 and in accord with large multi-national investigations and meta-analyses, male students showed a reduced rate of any anxiety syndrome, general anxiety syndrome, and somatoform syndrome as compared to female students, while the alcohol use syndrome was the only syndrome, for which male students showed significantly higher rates than female students (Bandelow \& Michaelis, 2015; De Waal et al., 2004; Galmiche et al., 2019; Grant et al., 2015; Hasin et al., 2018; Salk et al., 2017; World Health Organisation (WHO), 2017). Lower rates for male students in any depression syndrome or any eating syndrome did not remain statistically significant after correction for multiple testing.

Furthermore, male students showed a significantly lower current psychotherapy use and also a lower intention to use psychotherapy in the near future as compared to female students (see Table 1, Figure 2), which further corroborates previous reports from Germany or Switzerland (Brandstetter et al., 2017; Eggenberger et al., 2021; Rommel et al., 2018). However, when investigating gender differences in psychotherapy use by syndrome, only for the category any syndrome a significant difference was initially detected, which did not remain significant after correction for multiple testing. While for panic disorder syndrome proportionally more male students use psychotherapy than female students when affected, for all other syndromes, female students use psychotherapy proportionally more (see Figure $3 A)$. Examining the intention to use psychotherapy in those affected by any syndrome, male students reported significantly lower intention to take on psychotherapy. This, however, was also detected on syndrome level for major depressive syndrome, alcohol use syndrome, and any eating syndrome. Yet, after correcting for multiple testing only the category any syndrome remained statistically significant (see Figure 3B). As there are no gender-specific comparisons with regard to current or intended psychotherapy use by syndrome, these results provide 
important insights for future research on gender differences in psychotherapy use for specific disorders.

In order to answer the question about the predictive potential of attachment dimensions with regard to psychotherapy use, it is first necessary to clarify whether there are also gender differences in attachment dimensions in the present study. Confirming previous findings (Del Giudice, 2019), gender differences in attachment dimensions were corroborated (see Figure 1). Gender differences in attachment organization have been reported already thirty years ago (Dozier, 1990). However, due to imprecise use of attachment terminology and two different research backgrounds (developmental psychology [AAI] and personality psychology [ECR]), there is much confusion with respect to gender differences in attachment research. These two research approaches to quantifying attachment are entirely different methods, which is why the outcomes obtained cannot be compared in terms of gender differences in attachment organization in general. Nevertheless, when assessing attachment dimensions with self-report measures, men generally exhibit lower attachment anxiety and higher attachment avoidance (del Giudice, 2011). Insofar our study corroborates these results and highlights gender differences in attachment orientation as potential explanatory factor for lower psychotherapy use in men. Furthermore, it seems arguably necessary to additionally examine gender differences in attachment dimensions at the subgroup level and in a culturespecific manner (del Giudice, 2011; Li et al., 2009), with university students from Germany representing one such subgroup (Weber et al., 2020).

As shown in Figure 4, for the male and female sample, attachment anxiety emerged as significant predictor of current psychotherapy use. In the male sample attachment avoidance also emerged initially as significant predictor, but after correcting for multiple testing the association faded. However, for attachment anxiety a generally larger effect emerged suggesting attachment anxiety to be the more relevant behavior-regulating construct with regard to psychotherapy use. However, with regard to intention to use psychotherapy, in the total and the female sample attachment anxiety and avoidance significantly predicted intended psychotherapy use, while in the male sample only attachment anxiety was a significant predictor after correcting for multiple testing (see Figure 5). Again, attachment anxiety seems to be the more behavior-regulating construct in respect to intended psychotherapy use with consistently higher odds ratios, although the difference in effect size became less clear especially in the female subsample. When examining gender differences in 
the relationship between attachment organization and psychotherapy use (current \& intended), it is striking that a similar association appears to exist for all syndromes examined. However, it must be added here that due to power reduction in these specific subsample analyses, several associations no longer became statistically significant especially for the male sample by specific syndromes with regard to attachment avoidance (see S-Figure 1).

Many people seek psychotherapeutic support because of interpersonal problems caused by high attachment anxiety or avoidance. Insecure attachment operationalized as either high attachment anxiety or avoidance has consistently been associated with various psychiatric diagnoses (Bakermans-Kranenburg \& van IJzendoorn, 2009; Kirchmann et al., 2012). There are several studies further showing an association between insecure attachment and worse affect regulation (Bosquet \& Egeland, 2006), worse social skills (Belsky \& Fearon, 2002), more negative self-evaluations (Ann Easterbrooks \& Abeles, 2000), and worse problem solving competencies (Schieche \& Spangler, 2005). Therefore, it follows theoretically that these two constructs are positively associated with psychotherapy utilization. However, till date this has never been investigated and reported in a gender separate manner. Thus, this is the first study to show psychotherapy use to be positively associated with attachment anxiety and avoidance in a gender-specific manner.

In psychotherapy, the client-therapist relationship resembles an attachment relationship (Slade \& Holmes, 2019). Therefore, the finding that attachment avoidance is less strongly associated with psychotherapy use than attachment anxiety is plausible. Avoidantly attached individuals expect relevant others to be unavailable, unresponsive, or punitive (Mikulincer et al., 2013; Mikulincer \& Shaver, 2005). This causes insecurities for the potential psychotherapy clients, which are either overcome with courage and willpower, or are at a certain point no longer relevant enough due to the increasing psychological distress. This leads to the question of whether individuals with predominantly avoidant attachment issues, compared to individuals with predominantly anxious attachment issues, tend to enter psychotherapy at later stages of a disease course and exhibit correspondingly higher levels of distress. Indicative for this is that stronger attachment avoidance was associated with rejection of treatment providers, reduced self-disclosure, and poorer use of treatment (Dozier, 1990), while more securely attached individuals seem to benefit more from psychotherapy (Meredith et al., 2007). A secure attachment orientation with the therapist is 
associated with a better working alliance, more compliance and greater engagement in therapy (Diener \& Monroe, 2011; Dozier, 1990; Mikulincer et al., 2013).

Anxiously attached individuals, however, tend to depend on others for help with uncertainties and therefore tend to consider psychotherapy even when experiencing only minor psychological symptoms. In addition, anxiously attached people often have a negative view of themselves, so that they are generally more insecure whether they are "good" and "okay" as they are and might secretly wish to address this insecurity in psychotherapy when psychological symptoms arise (Mikulincer et al., 2013). This line of argumentation fits perfectly with the observed effect size difference in the predictive effect of the two attachment orientations on psychotherapy use with attachment anxiety being the more behavior-regulating construct.

Finally, we investigated in an explorative manner potential moderating effects of attachment anxiety and avoidance on the relation between suffering from a mental health syndrome and psychotherapy use (S-Figure $5 \mathrm{~A}-\mathrm{C}$ ). In the total sample, initially significant moderation effects were detected indicating that attachment anxiety moderated the association between any depressive syndrome and current psychotherapy use with higher attachment anxiety levels being associated with an increased likelihood of using psychotherapy. A similar effect was identified for the relation between somatoform syndrome and current psychotherapy use moderated by attachment anxiety. However, effects did not hold after correction for multiple testing. For the outcome intended psychotherapy, only in the female sample attachment avoidance emerged as significant moderator in combination with any depressive syndrome as predictor, which also did not remain significant after correction for multiple testing. In summary, with regard to the moderation analyses, it can be concluded that the findings provide an inconsistent picture, small effect size results, and therefore should be interpreted with caution.

\section{Limitations}

There are several limitations of the study when interpreting the results. First, the crosssectional nature of the study does not allow any conclusions about causality and large longitudinal designs are required to examine time-dependent associations. Second, gender was assessed only in a binary manner (Woman/Man). Although this was regular at the time the study was conducted, future studies would need to further separate the gender variable 
into the following categories: woman, man, transgender, cisgender, non-binary, other, or people preferring not to answer this question. Third, although the PHQ-D is a valid and reliable instrument for identifying mental disorders at the syndrome level, a clinical diagnostic interview would be preferable. Due to the lack of differential diagnostics in this instrument, it is not possible to determine conclusively whether for example a person with a positive screen for "any depression" is not primarily suffering from another mental disorder, e.g. anxiety disorders or substance use disorders, or even from a somatic disease, e.g. hypothyroidism. Fourth, the study was specifically mentioning mental stress in its title potentially biasing participation towards a convenience sample with comparably more mental health problems. Fifth, although widely discussed in the context of psychotherapy reluctance, the present study did not include a measure for traditional masculinity. Sixth, in terms of survey completion, 189 individuals did not complete the ECR-RD12. If it were assumed that these dropouts did not occur at random, they could possibly differ in a systematic way in attachment anxiety and avoidance due to the underlying group membership. However, the sensitivity analysis showed no differences in the results when only the reduced sample was used.

\section{Conclusion}

Lower attachment anxiety among male students compared with female students provides new insights with regard to lower psychotherapy use among mentally distressed male students. Since anxiously attached individuals suffer from a more negative view of the self rendering them more prone to hyperactivating strategies such as being overdependent on others and more often seeking reassurance or guidance, female students exhibiting overall higher levels in attachment anxiety use psychotherapy more often than men also because of this reason. As shown by logistic regressions, overall attachment anxiety is more behavior regulating than attachment avoidance with regard to psychotherapy use. Avoidantly attached individuals generally perceive others as unavailable, unresponsive, or punitive, which is associated with more deactivating strategies (e.g. avoiding emotional intimacy, denial of importance of emotional relationships). Therefore, higher attachment avoidance in male students cannot balance psychotherapy use between male and female students due to significantly higher attachment anxiety in female students and its stronger association with psychotherapy use. Public health campaigns to increase psychotherapy use among men should integrate these findings and general practitioners should be aware of this and support 
attachment avoidant men with mental health issues to overcome reluctance toward psychotherapy. Likewise, psychotherapy practitioners should consider and address their male clients' attachment organization due to an increased risk of psychotherapy dropout in avoidantly attached men.

\section{Declaration of interest}

All authors declare no conflicting interests.

\section{Acknowledgement}

We would like to thank all participants for participating in the study.

\section{Author contributions}

Design of study: RW; Participant recruitment: RW, CS; Data analysis and visualization: LE; Data interpretation: LE, AW, RW, CS; Writing of first draft: LE, AW; Editing subsequent versions of the manuscript: RW, AW, LE 


\section{References}

Ann Easterbrooks, M., \& Abeles, R. (2000). Windows to the self in 8-year-olds: Bridges to attachment representation and behavioral adjustment. Attachment \& Human Development, 2(1), 85-106.

Bakermans-Kranenburg, M., \& van IJzendoorn, M. H. (2009). The first 10,000 Adult Attachment Interviews: Distributions of adult attachment representations in clinical and non-clinical groups. Attachment and Human Development, 11(3), 223-263. https://doi.org/10.1080/14616730902814762

Bandelow, B., \& Michaelis, S. (2015). Epidemiology of anxiety disorders in the 21st century. Dialogues in Clinical Neuroscience, 17(3), 327.

Bartholomew, K., Kwong, M. J., \& Hart, S. D. (2001). Attachment.

Belsky, J., \& Fearon, R. M. P. (2002). Early attachment security, subsequent maternal sensitivity, and later child development: Does continuity in development depend upon continuity of caregiving? Attachment \& Human Development, 4(3), 361-387.

Bosquet, M., \& Egeland, B. (2006). The development and maintenance of anxiety symptoms from infancy through adolescence in a longitudinal sample. Development and Psychopathology, 18(2), 517-550.

Brandstetter, S., Dodoo-Schittko, F., Speerforck, S., Apfelbacher, C., Grabe, H. J., Jacobi, F., Hapke, U., Schomerus, G., \& Baumeister, S. E. (2017). Trends in non-help-seeking for mental disorders in Germany between 1997-1999 and 2009-2012: a repeated crosssectional study. Social Psychiatry and Psychiatric Epidemiology, 52(8), 1005-1013. https://doi.org/10.1007/s00127-017-1384-y

Brown, M. B., \& Forsythe, A. B. (1974). Robust tests for the equality of variances. Journal of the American Statistical Association, 69(346), 364-367. https://doi.org/10.1080/01621459.1974.10482955

Calzo, J. P. (2010). Determinants of variability in college men's sociosexuality: A focus on avoidance, bros, and masculinity ideologies. University of Michigan.

Cook, R. D. (1977). Detection of influential observation in linear regression. Technometrics, 19(1), 15-18. https://doi.org/10.1080/00401706.1977.10489493

Crowell, J. A., Fraley, R. C., \& Roisman, G. I. (2016). Measurement of Individual Differences in Adult Attachment. In J. Cassidy \& P. R. Shaver (Eds.), Handbook of Attachment: Theory, Research, and Clinical Applications (3rd ed., pp. 598-639). Guilford Press.

De Waal, M. W. M., Arnold, I. A., Eekhof, J. A. H., \& Van Hemert, A. M. (2004). Somatoform disorders in general practice: Prevalence, functional impairment and comorbidity with anxiety and depressive disorders. British Journal of Psychiatry, 184(JUNE), 470-476. https://doi.org/10.1192/bjp.184.6.470

del Giudice, M. (2011). Sex differences in romantic attachment: A meta-analysis. Personality and Social Psychology Bulletin, 37(2), 193-214. https://doi.org/10.1177/0146167210392789

Del Giudice, M. (2009). Sex, attachment, and the development of reproductive strategies. Behavioral and Brain Sciences, 32(1), 1-67. https://doi.org/10.1017/S0140525X09000016

Del Giudice, M. (2019). Sex differences in attachment styles. Current Opinion in Psychology, 25, 1-5. https://doi.org/10.1016/j.copsyc.2018.02.004

Del Giudice, M., \& Belsky, J. (2010). Sex differences in attachment emerge in middle childhood: An evolutionary hypothesis. Child Development Perspectives, 4(2), 97-105. https://doi.org/10.1111/j.1750-8606.2010.00125.x 
Diener, M. J., \& Monroe, J. M. (2011). The relationship between adult attachment style and therapeutic alliance in individual psychotherapy: A meta-analytic review.

Psychotherapy, 48(3), 237.

Dozier, M. (1990). Attachment organization and treatment use for adults with serious psychopathological disorders. Development and Psychopathology, 2(1), 47-60. https://doi.org/10.1017/S0954579400000584

Duschinsky, R., Bakkum, L., Mannes, J. M. M., Skinner, G. C. M., Turner, M., Mann, A., Coughlan, B., Reijman, S., Foster, S., \& Beckwith, H. (2021). Six attachment discourses: convergence, divergence and relay. Attachment and Human Development, 23(4), 355374. https://doi.org/10.1080/14616734.2021.1918448

Eggenberger, L. (2021). Masculinity Ideologies, Male-Typical Depression Symptoms, and Reduced Psychotherapy Use: Examining 407 Men Experiencing Psychological Distress [unpublished bachelor's thesis]. University of Zurich.

Eggenberger, L., Fordschmid, C., Ludwig, C., Weber, S., Grub, J., Komlenac, N., \& Walther, A. (2021). Men's Psychotherapy Use, Male Role Norms, and Male-Typical Depression Symptoms: Examining 716 Men and Women Experiencing Psychological Distress. Behavioral Sciences, 11(6), 83.

Ehrenthal, J. C., Dinger, U., Lamla, A., Funken, B., \& Schauenburg, H. (2008). Evaluation der deutschsprachigen Version des Bindungsfragebogens "Experiences in Close Relationships-Revised" (ECR-RD) (Evaluation of the German Version of the Attachment Questionnaire "Experiences in Close Relationships-Revised"[ECR-RD]). PPmP Psychotherapie · Psychosomatik · Medizinische Psychologie, 59(6), 215-223. https://doi.org/10.1055/s

Fitzpatrick, B. (2016). Men in Groups: Attachment and Masculinity. Pacifica Graduate Institute.

Fox, J., \& Monette, G. (1992). Generalized collinearity diagnostics. Journal of the American Statistical Association, 87(417), 178-183. https://doi.org/10.1080/01621459.1992.10475190

Fox, J., \& Sanford, W. (2019). An \{R\} Companion to Applied Regression, Third Edition. Sage.

Fraley, C. R., Niedenthal, P. M., Marks, M., Brumbaugh, C., \& Vicary, A. (2006). Adult attachment and the perception of emotional expressions: Probing the hyperactivating strategies underlying anxious attachment. Journal of Personality, 74(4), 1163-1190.

Fraley, R. C., Heffernan, M. E., Vicary, A. M., \& Brumbaugh, C. C. (2011). The experiences in close relationships-Relationship Structures Questionnaire: A method for assessing attachment orientations across relationships. Psychological Assessment, 23(3), 615.

Galmiche, M., Déchelotte, P., Lambert, G., \& Tavolacci, M. P. (2019). Prevalence of eating disorders over the 2000-2018 period: A systematic literature review. American Journal of Clinical Nutrition, 109(5), 1402-1413. https://doi.org/10.1093/ajcn/nqy342

Gillath, O., Bunge, S. A., Shaver, P. R., Wendelken, C., \& Mikulincer, M. (2005). Attachmentstyle differences in the ability to suppress negative thoughts: Exploring the neural correlates. Neuroimage, 28(4), 835-847.

Grant, B. F., Goldstein, R. B., Saha, T. D., Patricia Chou, S., Jung, J., Zhang, H., Pickering, R. P., June Ruan, W., Smith, S. M., Huang, B., \& Hasin, D. S. (2015). Epidemiology of DSM-5 alcohol use disorder results from the national epidemiologic survey on alcohol and related conditions III. JAMA Psychiatry, 72(8), 757-766.

https://doi.org/10.1001/jamapsychiatry.2015.0584

Grant, B. F., Saha, T. D., June Ruan, W., Goldstein, R. B., Patricia Chou, S., Jung, J., Zhang, H., Smith, S. M., Pickering, R. P., Huang, B., \& Hasin, D. S. (2016). Epidemiology of DSM-5 
drug use disorder results from the national epidemiologic survey on alcohol and related conditions-III. JAMA Psychiatry, 73(1), 39-47.

https://doi.org/10.1001/jamapsychiatry.2015.2132

Hasin, D. S., Sarvet, A. L., Meyers, J. L., Saha, T. D., Ruan, W. J., Stohl, M., \& Grant, B. F. (2018). Epidemiology of adult DSM-5 major depressive disorder and its specifiers in the United States. JAMA Psychiatry, 75(4), 336-346.

https://doi.org/10.1001/jamapsychiatry.2017.4602

Hayes, A. F. (2013). Introduction to mediation, moderation, and conditional process analysis: A regression-based approach. New York, NY: Guilford Press.

Jacobi, F., Höfler, M., Strehle, J., Mack, S., Gerschler, A., Scholl, L., Busch, M. A., Maske, U., Hapke, U., Gaebel, W., Maier, W., Wagner, M., Zielasek, J., \& Wittchen, H. U. (2014). Mental disorders in the general population. Study on the health of adults in Germany and the additional module mental health (DEGS1-MH). Nervenarzt, 85(1), 77-87. https://doi.org/10.1007/s00115-013-3961-y

Kirchmann, H., Steyer, R., Mayer, A., Joraschky, P., Schreiber-Willnow, K., \& Strauss, B. (2012). Effects of adult inpatient group psychotherapy on attachment characteristics: An observational study comparing routine care to an untreated comparison group. Psychotherapy Research, 22(1), 95-114.

Kirchmann, H., \& Strauß, B. (2008). Methoden zur Erfassung von Bindungsmerkmalen. Klinische Diagnostik Und Evaluation, 1(3), 293-327.

Leiner, D. J. (2019). SoSci Survey (Version 3.1.06) [Computer software].

Levant, R. F., Hall, R. J., Weigold, I. K., \& Mccurdy, E. R. (2016). Construct Validity Evidence for the Male Role Norms Inventory-Short Form: A Structural Equation Modeling Approach Using the Bifactor Model. Journal of Counseling Psychology, 63(5), 534-542. https://doi.org/10.1037/cou0000171.supp

Li, N., He, J., \& Li, T. (2009). Gender difference of insecure attachment: Universal or culturespecific? Behavioral and Brain Sciences, 32(1), 36-37.

Löwe, B., Spitzer, R. L., Gräfe, K., Kroenke, K., Quenter, A., Zipfel, S., Buchholz, C., Witte, S., \& Herzog, W. (2004). Comparative validity of three screening questionnaires for DSM-IV depressive disorders and physicians' diagnoses. Journal of Affective Disorders, 78(2), 131-140.

Löwe, B., Spitzer, R. L., Zipfel, S., \& Herzog, W. (2002). Manual: Komplettversion und Kurzform Autorisierte deutsche Version des „Prime MD Patient Health Questionnaire (PHQ)“. Nervenarzt, 2-11.

Mangiafico, S. (2021). rcompanion: Functions to support extension education program evaluation (2.4.0).

Meredith, P. J., Strong, J., \& Feeney, J. A. (2007). Adult attachment variables predict depression before and after treatment for chronic pain. European Journal of Pain, 11(2), 164-170.

Mikulincer, M., \& Shaver, P. R. (2005). Attachment theory and emotions in close relationships: Exploring the attachment-related dynamics of emotional reactions to relational events. Personal Relationships, 12(2), 149-168.

Mikulincer, M., Shaver, P. R., \& Berant, E. (2013). An attachment perspective on therapeutic processes and outcomes. Journal of Personality, 81(6), 606-616.

Mikulincer, M., Shaver, P. R., \& Pereg, D. (2003). Attachment theory and affect regulation: The dynamics, development, and cognitive consequences of attachment-related strategies. Motivation and Emotion, 27(2), 77-102.

Petrowski, K., Brähler, E., Suslow, T., \& Zenger, M. (2020). Revised short screening version of 
the attachment questionnaire for couples from the German general population. PLOS ONE, 15(4), 1-11. https://doi.org/10.1371/journal.pone.0230864

$\mathrm{R}$ Core Team. (2020). $R$ : A language and environment for statistical computing (4.0.3). $R$ Foundation for Statistical Computing, Vienna, Austria.

Revelle, W. (2020). psych: Procedures for personality and psychological research (2.1.3). Northwestern University, Evanston, Illinois, USA.

Richards, D. A., \& Schat, A. C. H. (2011). Attachment at (Not to) Work: Applying Attachment Theory to Explain Individual Behavior in Organizations. Journal of Applied Psychology, 96(1), 169-182. https://doi.org/10.1037/a0020372

Rommel, A., Bretschneider, J., Kroll, L., Prütz, F., \& Thom, J. (2018). Inanspruchnahme psychiatrischer und psychotherapeutischer Leistungen. Individuelle Determinanten und regionale Unterschiede. PPmP - Psychotherapie - Psychosomatik - Medizinische Psychologie, 68(08), e31-e31. https://doi.org/10.1055/s-0038-1667953

Rosenfield, S. (1999). Gender and mental health: Do women have more psychopathology, men more, or both the same (and why)?

Rosenfield, S., \& Smith, D. (2010). Gender and mental health: Do men and women have different amounts or types of problems. A Handbook for the Study of Mental Health: Social Contexts, Theories, and Systems, 256-267.

Saldubehere, A. (2019). The Relationships Between Traditional Masculinity Ideology, Alexithymia, and Attachment among Male Millennials in the United States. Alliant International University.

Salk, R. H., Hyde, J. S., \& Abramson, L. Y. (2017). Psychological Bulletin Gender Differences in Depression in Representative National Samples: Meta-Analyses of Diagnoses and Symptoms Gender Differences in Depression in Representative National Samples: MetaAnalyses of Diagnoses and Symptoms. Psychological Bulletin, 143(8), 783-822. https://doi.org/10.1037/bul0000102

Schieche, M., \& Spangler, G. (2005). Individual differences in biobehavioral organization during problem-solving in toddlers: The influence of maternal behavior, infant-mother attachment, and behavioral inhibition on the attachment-exploration balance. Developmental Psychobiology: The Journal of the International Society for Developmental Psychobiology, 46(4), 293-306.

Seidler, Z. E., Dawes, A. J., Rice, S. M., Oliffe, J. L., \& Dhillon, H. M. (2016). The role of masculinity in men's help-seeking for depression: A systematic review. Clinical Psychology Review, 49, 106-118. https://doi.org/10.1016/j.cpr.2016.09.002

Seidler, Z. E., Wilson, M. J., Kealy, D., Oliffe, J. L., Ogrodniczuk, J. S., \& Rice, S. M. (2021). Men's Dropout From Mental Health Services: Results From a Survey of Australian Men Across the Life Span. American Journal of Men's Health, 15(3), 15579883211014776.

Slade, A., \& Holmes, J. (2019). Attachment and psychotherapy. Current Opinion in Psychology, 25(1), 152-156. https://doi.org/10.1016/j.copsyc.2018.06.008

Smiler, A. P., \& Heasley, R. (2016). Boys' and men's intimate relationships: Friendships and romantic relationships. In APA handbook of men and masculinities. (pp. 569-589). American Psychological Association.

Spitzer, R. L., Kroenke, K., Williams, J. B. W., Group, P. H. Q. P. C. S., \& Group, P. H. Q. P. C. S. (1999). Validation and utility of a self-report version of PRIME-MD: the PHQ primary care study. Jama, 282(18), 1737-1744.

Vos, T., Abajobir, A. A., Abbafati, C., Abbas, K. M., Abate, K. H., Abd-Allah, F., ..., \& Murray, C. J. L. (2017). Global, regional, and national incidence, prevalence, and years lived with disability for 328 diseases and injuries for 195 countries, 1990 - 2016: a systematic 
analysis for the Global Burden of Disease Study 2016. Lancet, 390, 1211-1259. https://doi.org/10.1016/S0140-6736(17)32154-2

Walther, A, Grub, J., Ehlert, U., Wehrli, S., Rice, S., Seidler, Z. E., \& Debelak, R. (2021). Male depression risk, psychological distress, and psychotherapy uptake: validation of the German version of the male depression risk scale. Journal of Affective Disorders Reports, 100107. https://doi.org/https://doi.org/10.1016/j.jadr.2021.100107

Walther, Andreas, \& Seidler, Z. E. (2020). Männliche Formen der Depression und deren Behandlung. PiD-Psychotherapie Im Dialog, 21(04), 40-45. https://doi.org/10.1055/a0987-5902

Weber, R., Ehrenthal, J. C., Pförtner, T. K., Albus, C., \& Stosch, C. (2020). Die schönste Zeit des Lebens? Zeitschrift Für Klinische Psychologie Und Psychotherapie, 49(1), 43-51. https://doi.org/10.1026/1616-3443/a000573

Wickham, H. (2016). ggplot2: Elegant graphics for data analysis. Springer-Verlag, New York.

Wong, Y. J., Ho, M. H. R., Wang, S. Y., \& Miller, I. S. K. (2017). Meta-analyses of the relationship between conformity to masculine norms and mental health-related outcomes. Journal of Counseling Psychology, 64(1), 80-93. https://doi.org/10.1037/cou0000176

World Health Organisation (WHO). (2017). Depression and Other Common Mental Disorders Global Health Estimates. https://doi.org/(WHO reference number: WHO/MSD/MER/2017.2) 
Table 1. Descriptive Statistics for the Sample

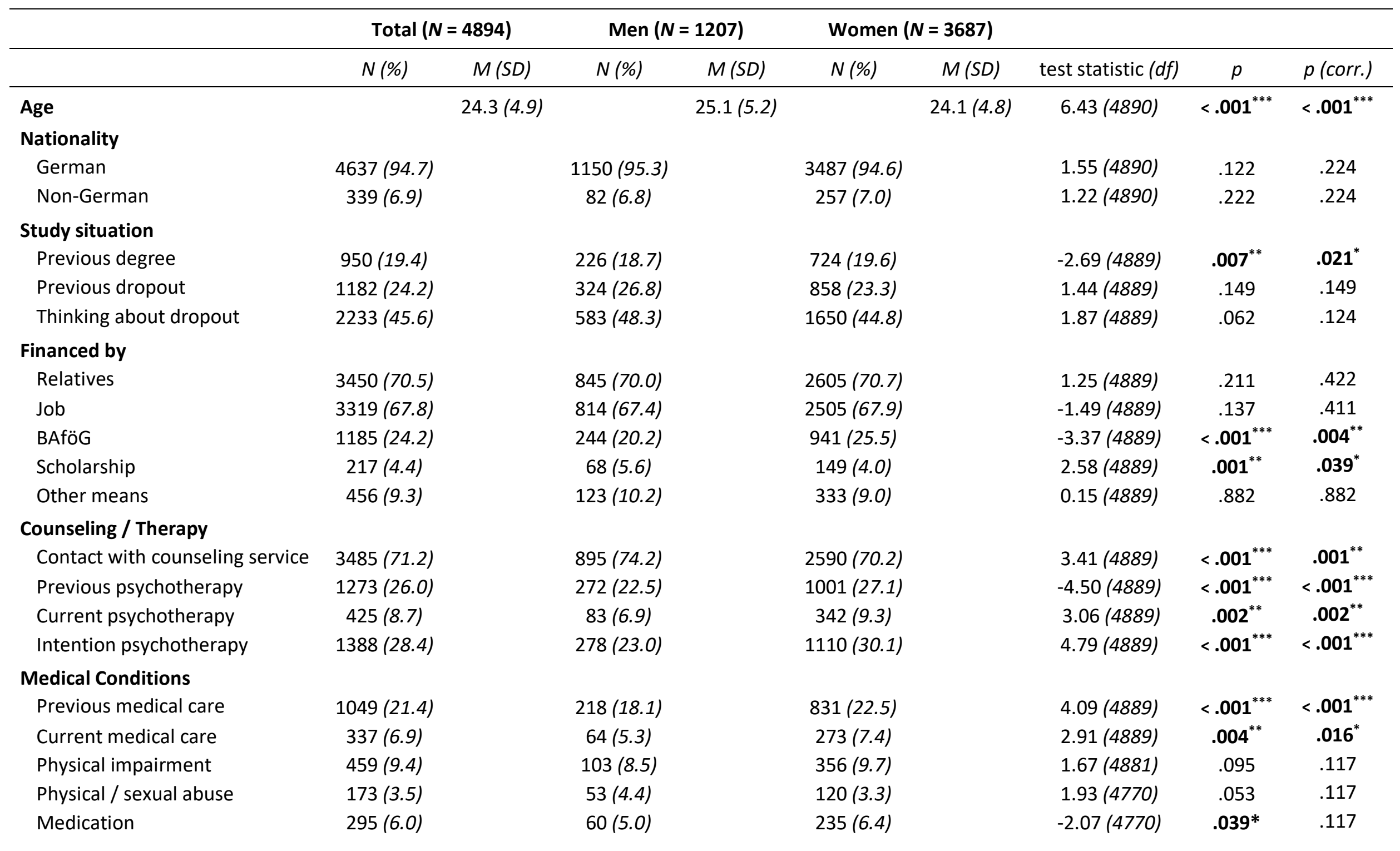




\section{Psychiatric Syndromes}

\section{Any syndrome}

2856 (58.4)

Any depressive

$1710(34.9)$

Minor depression

703 (14.4)

1007 (20.6)

Major depression

614 (12.5)

$114(2.3)$

Anxiety-panic

549 (11.2)

Anxiety-generalized

934 (19.1)

1157 (23.6)

576 (11.8)

Any eating disorder

$136(2.8)$

441 (9.0)
678 (56.2)

392 (32.5)

156 (12.9)

236 (19.6)

$109(9.0)$

21 (1.7)

101 (8.4)

340 (28.2)

$128(10.6)$

$123(10.2)$

$29(2.4)$

$94(7.8)$
2178 (59.1)

$1318(35.7)$

547 (14.8)

771 (20.9)

505 (13.7)

$93(2.5)$

448 (12.2)

594 (16.1)

1029 (27.9)

$453(12.3)$

107 (2.9)

347 (9.4)
$2.86(1.41)$

$2.47(1.23)$

$\begin{array}{cccc} & -1.72(4889) & .085 & .399 \\ -2.05(4887) & .040^{*} & .322 \\ -1.51(4887) & .130 & .399 \\ -1.10(4887) & .271 & .542 \\ -4.51(4889) & <.001^{* * *} & <.001^{* * *} \\ -1.75(4889) & .080 & 0.3985 \\ & -3.82(4889) & <.001^{* * *} & .001^{* *} \\ & -9.52(4889) & <.001^{* * *} & <.001^{* * *} \\ & -11.71(4889) & <.001^{* * *} & <.001^{* * *} \\ & -2.01(4889) & .044^{*} & .322 \\ & -0.85(4541) & .398 & .542 \\ & -1.84(4889) & .065 & .391 \\ & & & \\ 2.92(1.41) & -4.80(4700) & <.001^{* * *} & <.001^{* * *} \\ 2.40(1.22) & 6.88(4700) & <.001^{* * *} & <.001^{* * *}\end{array}$

\subsection{9 (1.39)}

$2.69(1.25)$
Note. $N=$ number of participants, $M=$ mean, $S D=$ standard deviation, $d f=$ degrees of freedom, $p=p$-value, test statistic $=t$-value for continuous and $z$-score for categorical variables. corr. $=$ Holm-Bonferroni adjustment for multiple testing.

${ }^{a}$ ECR-RD12 = Experiences in Close Relationship - Revised 


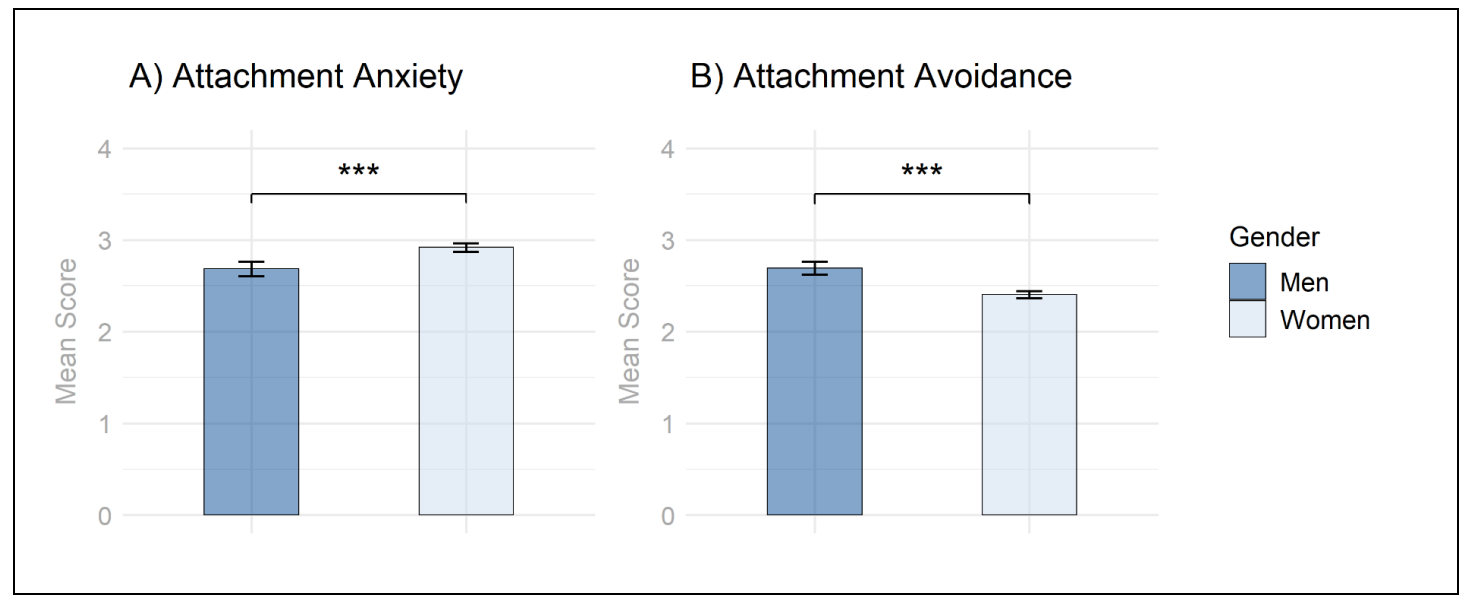

Figure 1. Gender Differences regarding Attachment Dimensions

Note. $p$-values were adjusted for multiple testing using the Holm-Bonferroni method.

$* * *=p<.001$

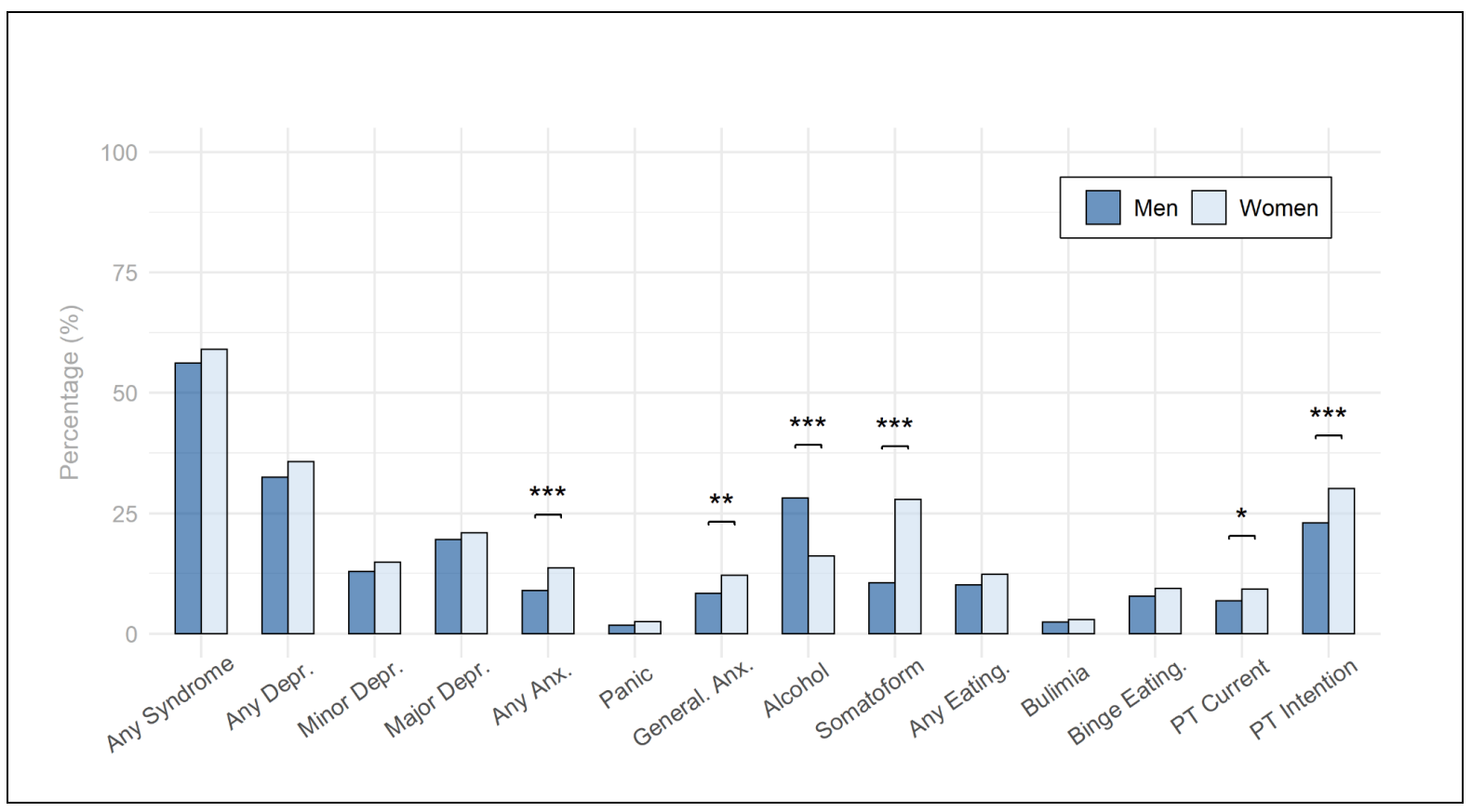

Figure 2. Gender Differences regarding Screened Psychiatric Syndromes and Psychotherapy Use Note. Depr. $=$ Depression, Anx. = Anxiety, General. = Generalized, Eating. = Eating disorder, $P T=$ Psychotherapy. $p$-values were adjusted for multiple testing using the Holm-Bonferroni method. $*=p<.05,{ }^{* *}=p<.01,{ }^{* * *}=p<.001$ 
A) Current Psychotherapy Use

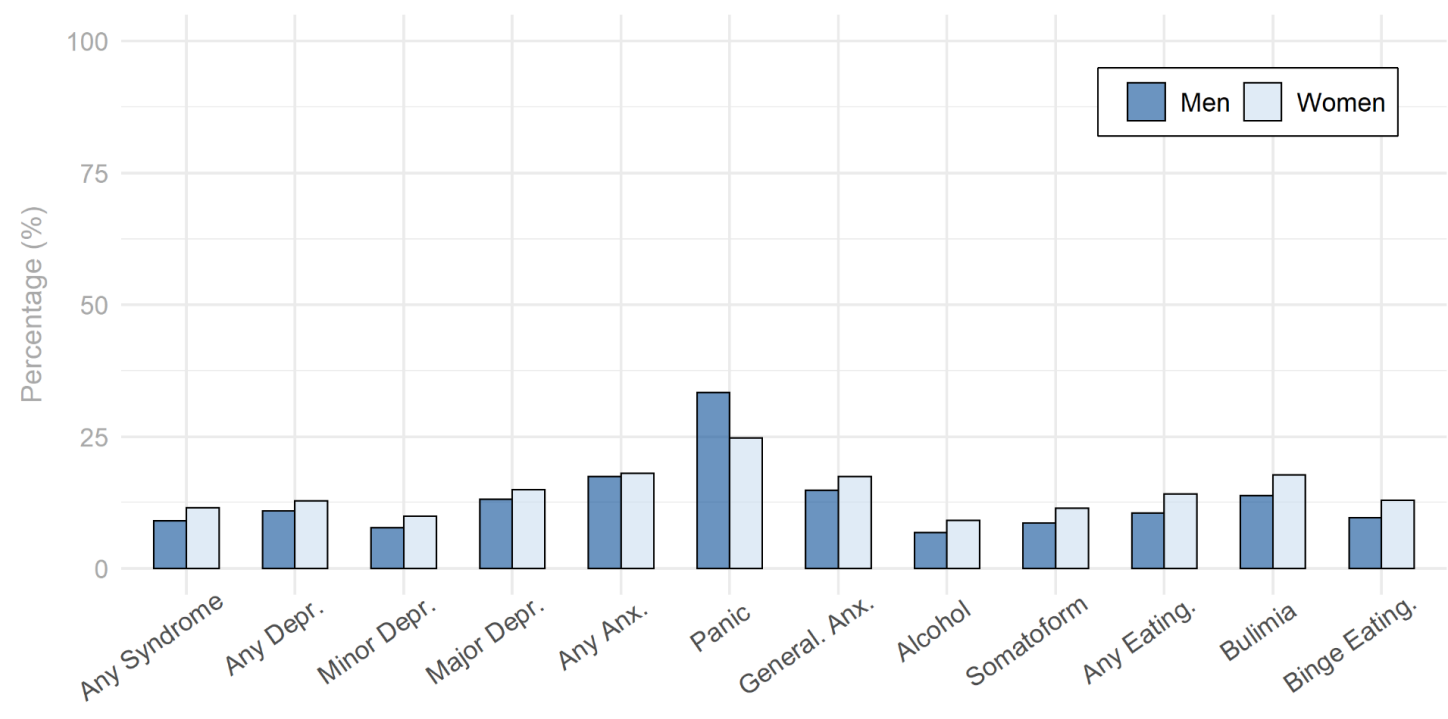

B) Intention to Start Psychotherapy

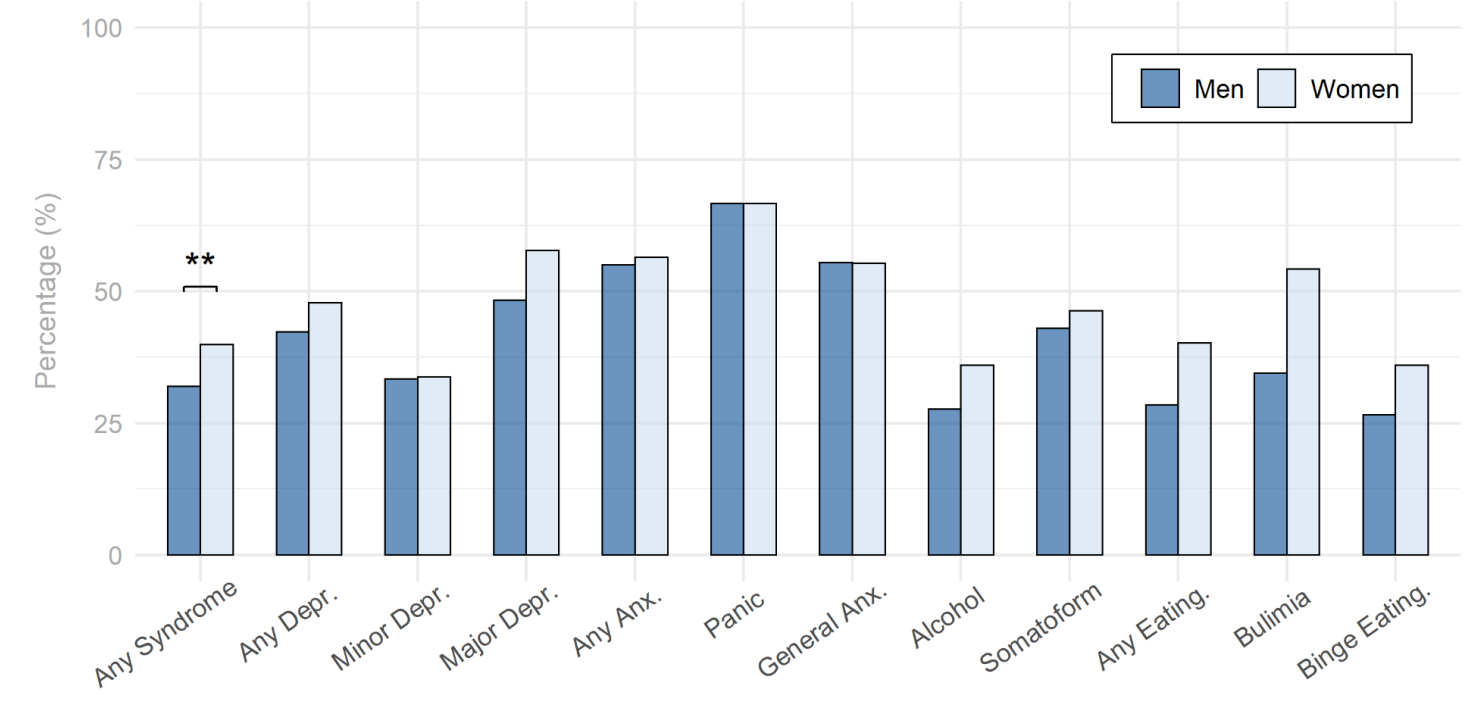

Figure 3. Gender Differences regarding Psychotherapy Use in different Syndromic Subgroups Note . Depr. $=$ Depression, Anx.$=$ Anxiety, General. $=$ Generalized, Eating. $=$ Eating disorder,$P T$ $=$ Psychotherapy. $p$-values were adjusted for multiple testing using the Holm-Bonferroni method.

$* *=p<.01$ 


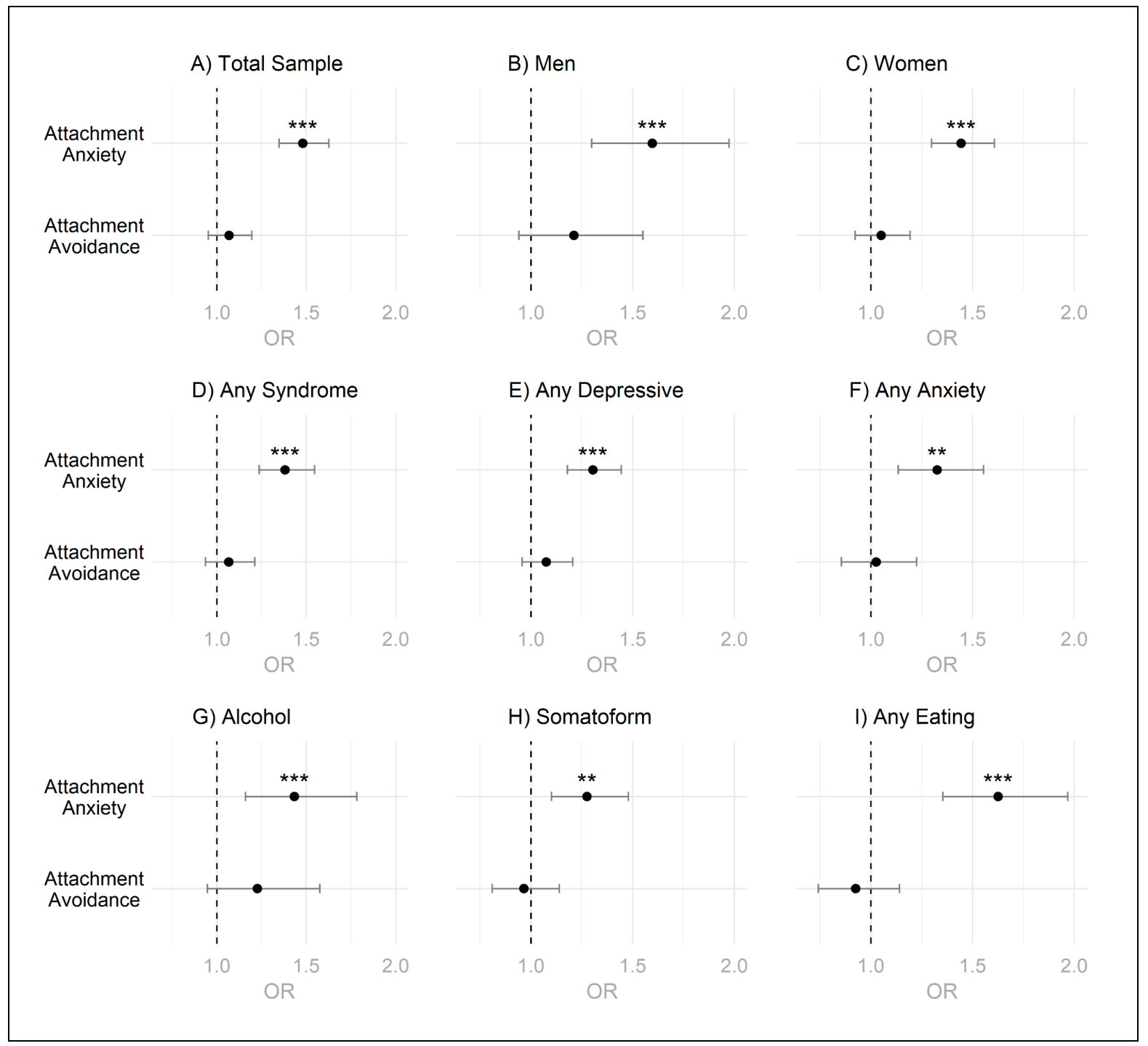

Figure 4. Odds Ratios for Attachment Dimensions and Current Psychotherapy Use Note. $O R=$ Odds Ratio. $p$-values were adjusted for multiple testing using the Holm-Bonferroni method.

$*=p<.05,{ }^{* *}=p<.01, * * *=p<.001$ 


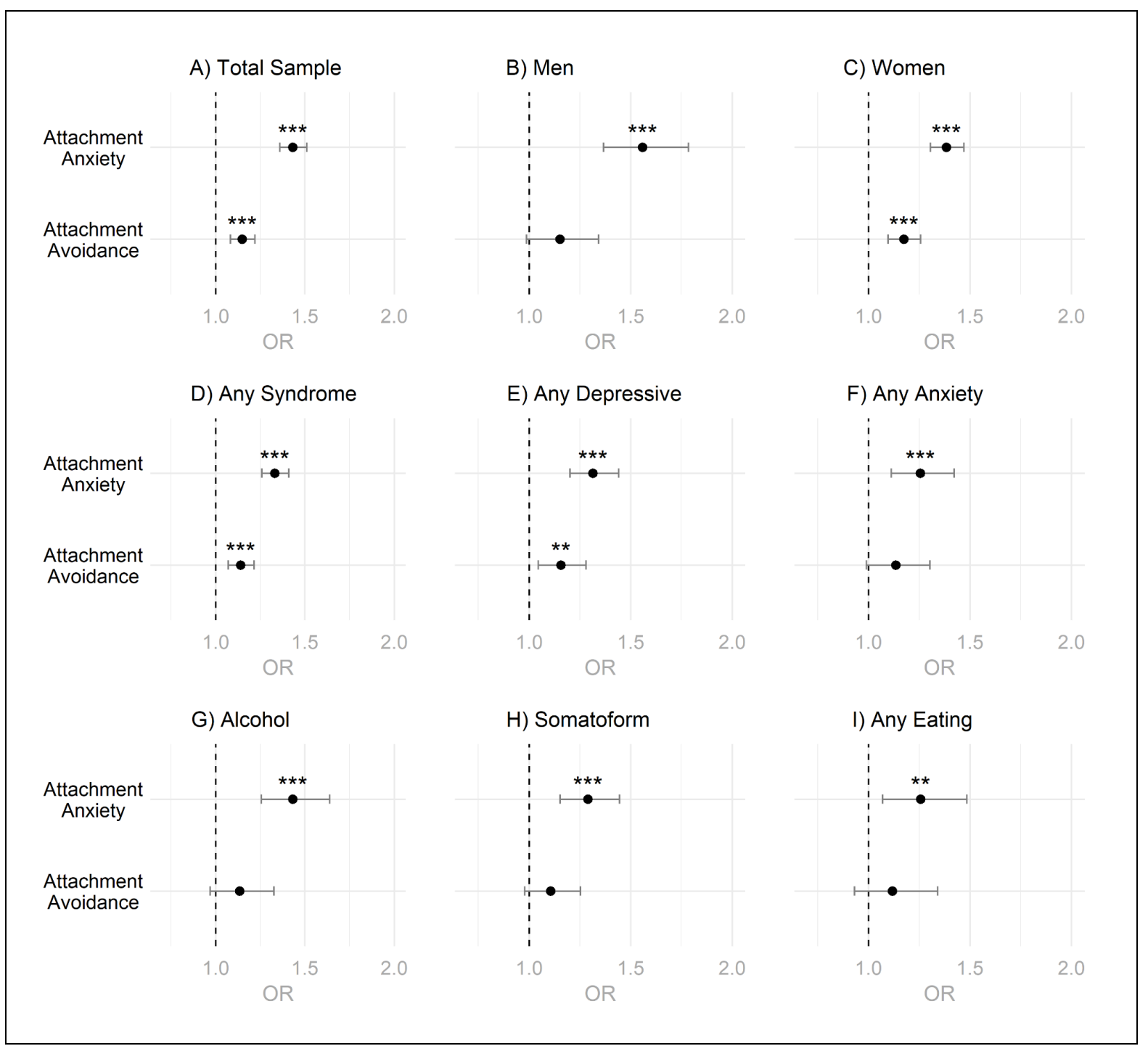

Figure 5. Odds Ratios for Attachment Dimensions and the Intention to Start Psychotherapy Note. $O R=$ Odds Ratio. $p$-values were adjusted for multiple testing using the Holm-Bonferroni method.

$*=p<.05, * *=p<.01, * * *=p<.001$ 


\section{Gender differences in attachment anxiety and avoidance and their association with psychotherapy use - Examining students from a German university}

Weber, R. ${ }^{1}$, Eggenberger, L. ${ }^{2}$, Stosch, C. ${ }^{3}$, Walther, A. ${ }^{2,}$

${ }^{1}$ University of Cologne, Faculty of Medicine and University Hospital Cologne, Clinic and Polyclinic for Psychosomatics and Psychotherapy, Germany

${ }^{2}$ Clinical Psychology and Psychotherapy, University of Zurich, Zurich, Switzerland

${ }^{3}$ Student Deans Office, Medical Faculty, University of Cologne, Germany

* Correspondence

\section{Supplementary material}

\section{Content}

S-Table 1: Logistic Regression Models predicting current Psychotherapy Use

page 2

S-Table 2: Logistic Regression Models predicting Intention to Start Psychotherapy

page 3

S-Figure 1: Odds Ratios for current Psychotherapy Use for Male Students

page 4

S-Figure 2: Odds Ratios for current Psychotherapy Use for Feale Students

page 5

S-Figure 3: Odds Ratios for Intention to Start Psychotherapy for Male Students

page 6

S-Figure 4: Odds Ratios for Intention to Start Psychotherapy for Female Students

page 7

Exploratory moderation analysis: Results

page 8

S-Figure 5: Significant Moderations

page 9 
S-Table 1. Logistic Regression Models predicting current Psychotherapy Use

\begin{tabular}{|c|c|c|c|c|c|c|}
\hline Subsample & Predictor & $\beta(S E)$ & $p$ & $p$ (corr.) & $R^{2}$ & AIC \\
\hline \multirow{2}{*}{ Total } & Attachment Anxiety & $0.39(0.04)$ & $<.001^{* * *}$ & $<.001^{* * *}$ & \multirow[b]{2}{*}{.13} & \multirow[b]{2}{*}{2619} \\
\hline & Attachment Avoidance & $0.07(0.04)$ & .135 & .942 & & \\
\hline \multirow{2}{*}{ Men } & Attachment Anxiety & $0.47(0.08)$ & $<.001^{* * *}$ & $<.001^{* * *}$ & \multirow[b]{2}{*}{.16} & \multirow[b]{2}{*}{538} \\
\hline & Attachment Avoidance & $0.19(0.10)$ & $.046^{*}$ & .370 & & \\
\hline \multirow[b]{2}{*}{ Women } & Attachment Anxiety & $0.37(0.04)$ & $<.001^{* * *}$ & $<.001^{* * *}$ & \multirow[b]{2}{*}{.12} & \multirow[b]{2}{*}{2082} \\
\hline & Attachment Avoidance & $0.05(0.05)$ & .328 & 1 & & \\
\hline \multirow{2}{*}{ Any syndrome } & Attachment Anxiety & $0.32(0.04)$ & $<.001^{* * *}$ & $<.001^{* * *}$ & \multirow[b]{2}{*}{.13} & \multirow[b]{2}{*}{1801} \\
\hline & Attachment Avoidance & $0.06(0.05)$ & .202 & 1 & & \\
\hline \multirow{2}{*}{$\begin{array}{l}\text { Any depressive } \\
\text { syndrome }\end{array}$} & Attachment Anxiety & $0.27(0.05)$ & $<.001^{* * *}$ & $<.001^{* * *}$ & \multirow[b]{2}{*}{.10} & \multirow[b]{2}{*}{1199} \\
\hline & Attachment Avoidance & $0.07(0.06)$ & .218 & 1 & & \\
\hline \multirow{2}{*}{$\begin{array}{l}\text { Any anxiety } \\
\text { syndrome }\end{array}$} & Attachment Anxiety & $0.28(0.07)$ & $<.001^{* * *}$ & $.001^{* *}$ & \multirow[b]{2}{*}{.09} & \multirow[b]{2}{*}{554} \\
\hline & Attachment Avoidance & $0.03(0.08)$ & .761 & 1 & & \\
\hline \multirow{2}{*}{$\begin{array}{l}\text { Alcohol use } \\
\text { syndrome }\end{array}$} & Attachment Anxiety & $0.36(0.08)$ & $<.001^{* * *}$ & $<.001^{* * *}$ & \multirow[b]{2}{*}{.14} & \multirow[b]{2}{*}{487} \\
\hline & Attachment Avoidance & $0.20(0.10)$ & $.039 *$ & 0.349 & & \\
\hline \multirow{2}{*}{$\begin{array}{l}\text { Somatoform } \\
\text { syndrome }\end{array}$} & Attachment Anxiety & $0.24(0.07)$ & $<.001^{* * *}$ & $.003^{* *}$ & \multirow[b]{2}{*}{.11} & \multirow[b]{2}{*}{757} \\
\hline & Attachment Avoidance & $-0.04(0.08)$ & .650 & 1 & & \\
\hline \multirow{2}{*}{$\begin{array}{l}\text { Any eating } \\
\text { disorder }\end{array}$} & Attachment Anxiety & $0.49(0.10)$ & $<.001^{* * *}$ & $<.001^{* * *}$ & \multirow{2}{*}{.28} & \multirow[b]{2}{*}{373} \\
\hline & Attachment Avoidance & $-0.08(0.11)$ & 0.471 & 1 & & \\
\hline
\end{tabular}

Note. $\beta$ = estimated regression coefficient, $S E=$ standard error, $p=p$-value, $R^{2}=$ Nagelkerke's maximumlikelihood estimation for pseudo $R$-squared, AIC = Akaike Information Criterion. All calculations were controlled for age and nationality. corr. $=p$-values were adjusted for multiple testing using the HolmBonferroni method.

${ }^{*}=p<.05,{ }^{* *}=p<.01,{ }^{* * *}=p<.001$ 
S-Table 2. Logistic Regression Models predicting Intention to Start Psychotherapy

\begin{tabular}{|c|c|c|c|c|c|c|}
\hline Subsample & Predictor & $\beta(S E)$ & $p$ & $p$ (corr.) & $R^{2}$ & AIC \\
\hline \multirow{2}{*}{ Total } & Attachment Anxiety & $0.36(0.02)$ & $<.001^{* * *}$ & $<.001^{* * *}$ & \multirow[b]{2}{*}{.15} & \multirow[b]{2}{*}{5330} \\
\hline & Attachment Avoidance & $0.14(0.03)$ & $<.001^{* * *}$ & $<.001^{* * *}$ & & \\
\hline \multirow{2}{*}{ Men } & Attachment Anxiety & $0.44(0.05)$ & $<.001^{* * *}$ & $<.001^{* * *}$ & \multirow[b]{2}{*}{.18} & \multirow[b]{2}{*}{1162} \\
\hline & Attachment Avoidance & $0.14(0.06)$ & $.017^{*}$ & .087 & & \\
\hline \multirow[b]{2}{*}{ Women } & Attachment Anxiety & $0.32(0.03)$ & $<.001^{* * *}$ & $<.001^{* * *}$ & \multirow[b]{2}{*}{.14} & \multirow[b]{2}{*}{4150} \\
\hline & Attachment Avoidance & $0.16(0.03)$ & $<.001^{* * *}$ & $<.001^{* * *}$ & & \\
\hline \multirow{2}{*}{ Any syndrome } & Attachment Anxiety & $0.29(0.03)$ & $<.001^{* * *}$ & $<.001^{* * *}$ & \multirow[b]{2}{*}{.14} & \multirow[b]{2}{*}{3499} \\
\hline & Attachment Avoidance & $0.13(0.03)$ & $<.001^{* * *}$ & $<.001^{* * *}$ & & \\
\hline \multirow{2}{*}{$\begin{array}{l}\text { Any depressive } \\
\text { syndrome }\end{array}$} & Attachment Anxiety & $0.27(0.04)$ & $<.001^{* * *}$ & $<.001^{* * *}$ & \multirow[b]{2}{*}{.13} & \multirow[b]{2}{*}{2198} \\
\hline & Attachment Avoidance & $0.15(0.04)$ & $<.001^{* * *}$ & $.002^{* *}$ & & \\
\hline \multirow{2}{*}{$\begin{array}{l}\text { Any anxiety } \\
\text { syndrome }\end{array}$} & Attachment Anxiety & $0.23(0.06)$ & $<.001^{* * *}$ & $<.001^{* * *}$ & \multirow[b]{2}{*}{.11} & \multirow[b]{2}{*}{804} \\
\hline & Attachment Avoidance & $0.13(0.06)$ & $.047^{*}$ & .147 & & \\
\hline \multirow{2}{*}{$\begin{array}{l}\text { Alcohol use } \\
\text { syndrome }\end{array}$} & Attachment Anxiety & $0.36(0.05)$ & $<.001^{* * *}$ & $<.001^{* * *}$ & \multirow[b]{2}{*}{.14} & \multirow[b]{2}{*}{1098} \\
\hline & Attachment Avoidance & $0.13(0.06)$ & $.039^{*}$ & .147 & & \\
\hline \multirow{2}{*}{$\begin{array}{l}\text { Somatoform } \\
\text { syndrome }\end{array}$} & Attachment Anxiety & $0.25(0.04)$ & $<.001^{* * *}$ & $<.001^{* * *}$ & \multirow[b]{2}{*}{.12} & \multirow[b]{2}{*}{1502} \\
\hline & Attachment Avoidance & $0.1(0.05)$ & $.037^{*}$ & .147 & & \\
\hline \multirow{2}{*}{$\begin{array}{l}\text { Any eating } \\
\text { disorder }\end{array}$} & Attachment Anxiety & $0.23(0.06)$ & $<.001^{* * *}$ & $<.001^{* * *}$ & \multirow[b]{2}{*}{.26} & \multirow[b]{2}{*}{663} \\
\hline & Attachment Avoidance & $0.11(0.07)$ & .119 & .147 & & \\
\hline
\end{tabular}

Note. $\beta=$ estimated regression coefficient, $S E=$ standard error, $p=p$-value, $R^{2}=$ Nagelkerke's maximumlikelihood estimation for pseudo $R$-squared, AIC = Akaike Information Criterion. All calculations were controlled for age and nationality. corr. $=p$-values were adjusted for multiple testing using the HolmBonferroni method.

${ }^{*}=p<.05,{ }^{* *}=p<.01,{ }^{* * *}=p<.001$ 


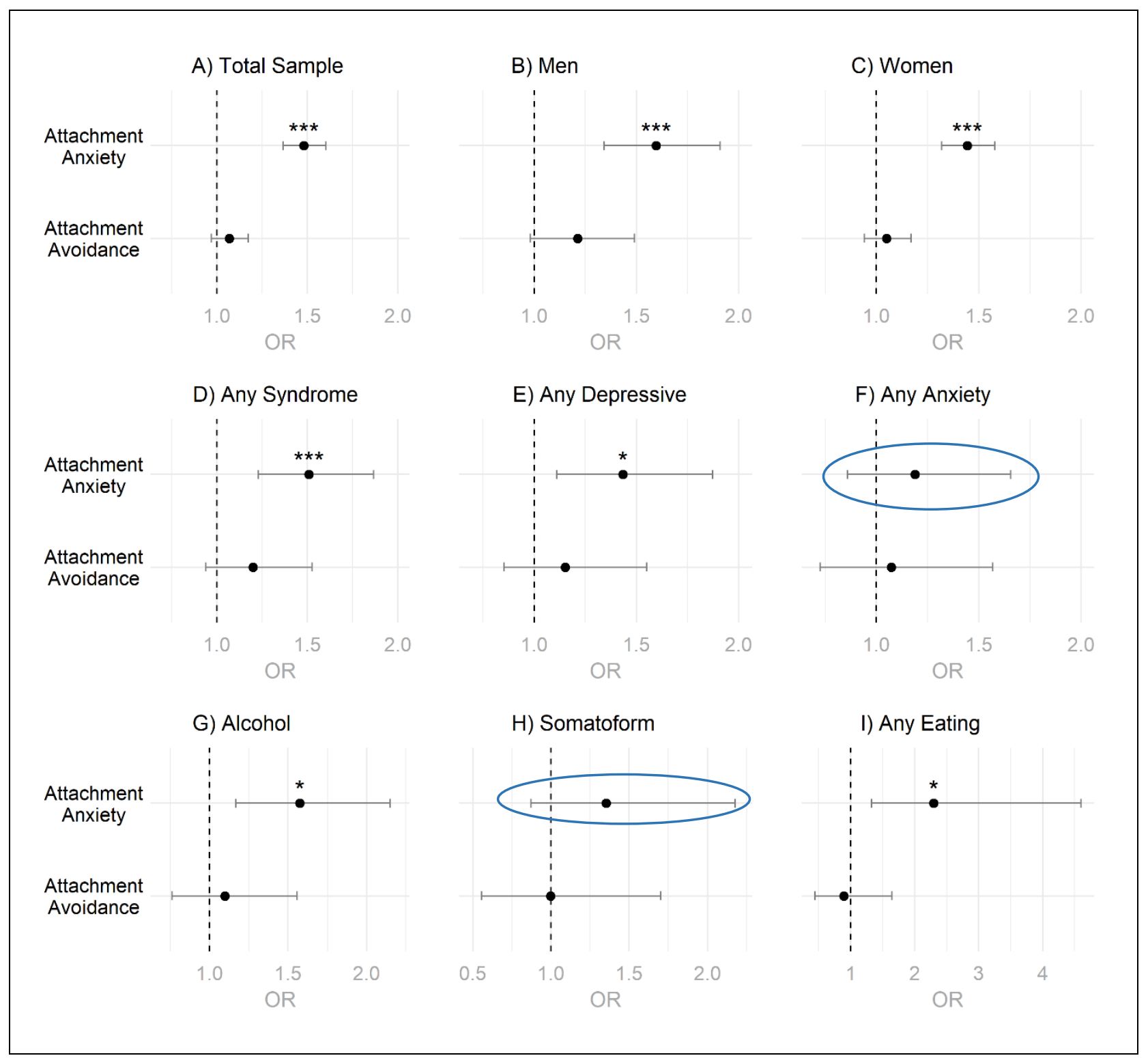

S-Figure 1. Odds Ratios for current Psychotherapy Use for Male Students

Note. $O R=$ Odds Ratio. The error bars indicate a 95\% confidence interval and the blue highlightings mark significant changes as compared to the total sample (Figure 4). All calculations were controlled for age and nationality. $p$-values were adjusted for multiple testing using the Holm-Bonferroni method. ${ }^{*}=p<.05,{ }^{* *}=p<.01,{ }^{* * *}=p<.001$ 


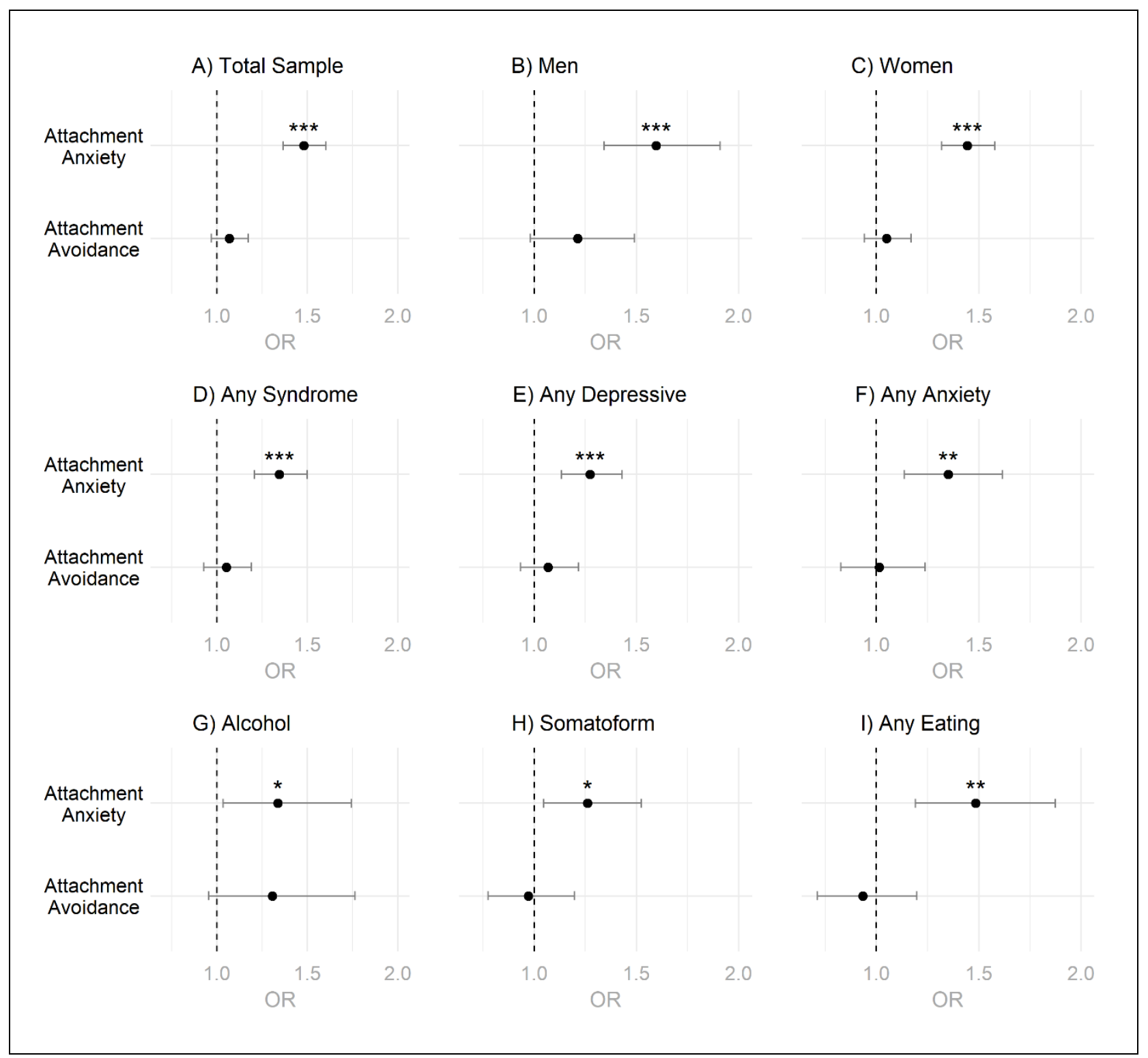

S-Figure 2. Odds Ratios for current Psychotherapy Use for Female Students

Note. $O R=$ Odds Ratio. The error bars indicate a $95 \%$ confidence interval. There were no significant changes compared to the total sample (Figure 4). All calculations were controlled for age and nationality. $p$-values were adjusted for multiple testing using the Holm-Bonferroni method. ${ }^{*}=p<.05,{ }^{* *}=p<.01,{ }^{* * *}=p<.001$ 


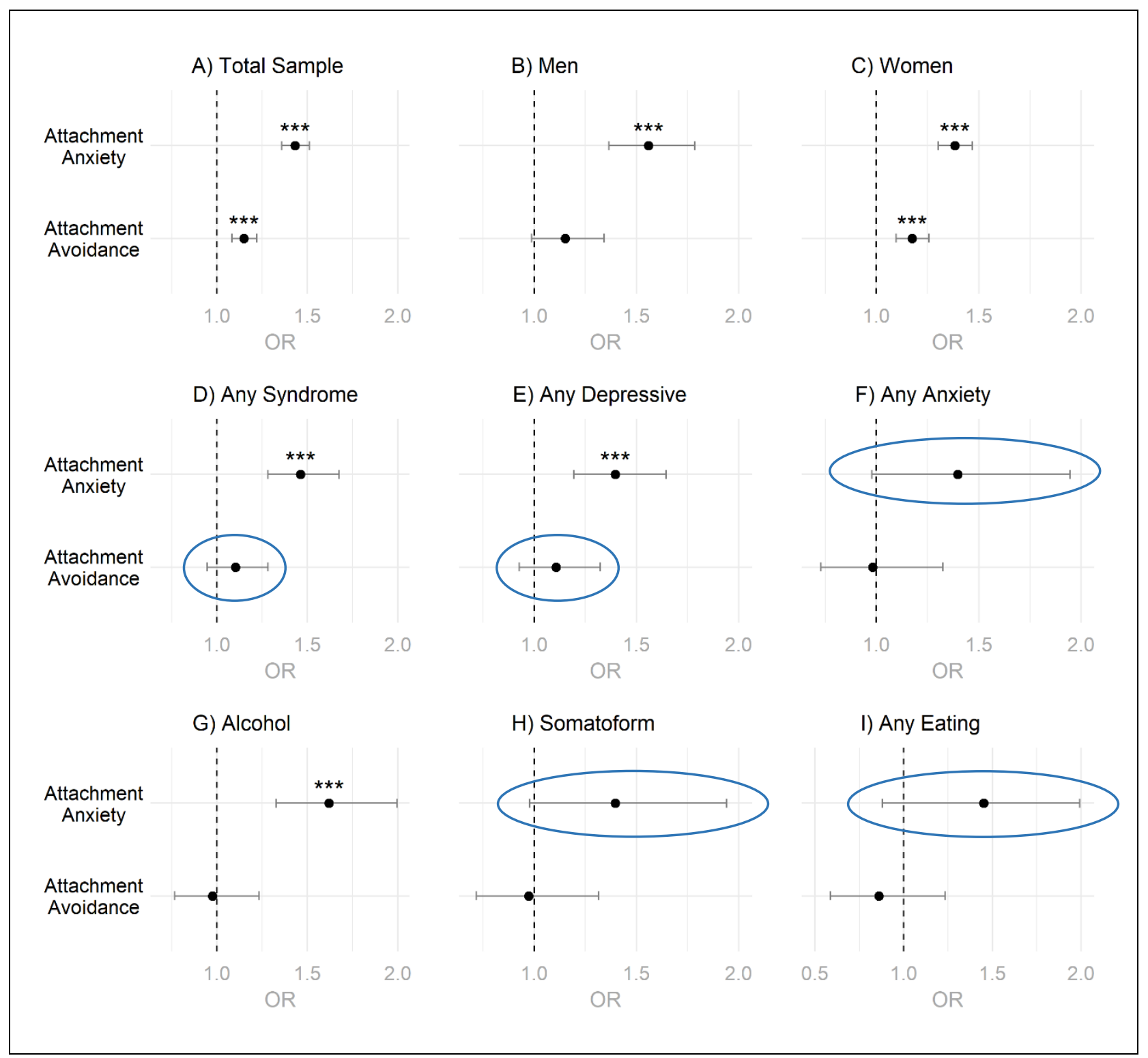

S-Figure 3. Odds Ratios for Intention to Start Psychotherapy for Male Students

Note. $O R=$ Odds Ratio. The error bars indicate a 95\% confidence interval and the blue highlightings mark significant changes as compared to the total sample (Figure 5). All calculations were controlled for age and nationality. $p$-values were adjusted for multiple testing using the Holm-Bonferroni method. ${ }^{*}=p<.05,{ }^{* *}=p<.01,{ }^{* * *}=p<.001$ 


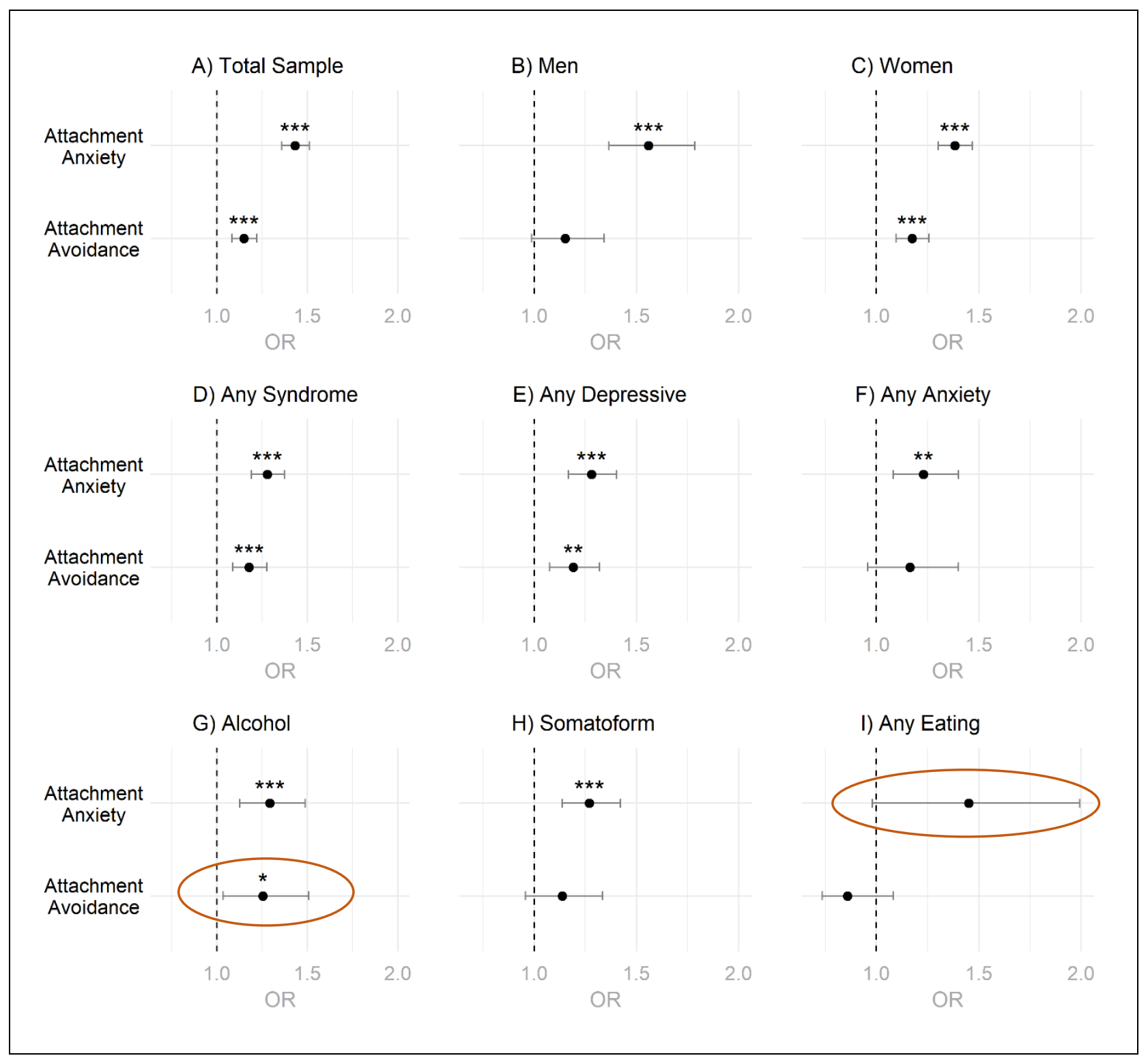

S-Figure 4. Odds Ratios for Intention to Start Psychotherapy for Female Students

Note. $O R=$ Odds Ratio. The error bars indicate a $95 \%$ confidence interval and the orange highlightings mark significant changes as compared to the total sample (Figure 5). All calculations were controlled for age and nationality. $p$-values were adjusted for multiple testing using the Holm-Bonferroni method. ${ }^{*}=p<.05,{ }^{* *}=p<.01,{ }^{* * *}=p<.001$ 


\section{Exploratory moderation analysis - Results}

Explorative moderation analyses were further conducted to detect possible moderating effects of attachment orientation on the association of individual syndromes and psychotherapy use. Moderation analyses were conducted using Hayes' (2013) regression-based approach to test for possible moderating effects of attachment orientation on the association between the likelihood to use or the intention to start psychotherapy and the positive screening for different psychiatric syndromes. Subsequently described significant moderation effects did not survive correction for multiple testing, suggesting that the results should be considered preliminary findings providing a basis for future research and a call for replication.

In a first part, where current psychotherapy use was the outcome, the only two significant interaction effects were observed for attachment anxiety on the association between current psychotherapy use and any depressive syndrome $\left(z[4697]=2.35, p=.019\right.$, Nagelkerke $R^{2}=.136$., AIC $=2601.6)$ and somatoform syndrome $\left(z[4697]=-2.51, p=.012\right.$, Nagelkerke $\left.R^{2}=.135, \mathrm{AIC}=2603.1\right)$, respectively (S-Figure 5A-5B). Both interactions indicate that students screened negative for any depressive or somatoform syndrome are more likely to currently use psychotherapy when exhibiting higher attachment anxiety as compared to students screened negative for any depressive or somatoform syndrome who exhibit lower attachment anxiety. The same interactions were also be observed in the female subsample (any depressive syndrome: $z[3542]=2.10, p=.036$, Nagelkerke $R^{2}$ $=.129, \mathrm{AIC}=2069.3$; somatoform syndrome: $z[3542]=-2.13, p=.033$, Nagelkerke $R^{2}=.129, \mathrm{AIC}=$ 2069.9), but not in the male subsample (any depressive syndrome: $z[1147]=0.87, p=.387$, Nagelkerke $R^{2}=.168, \mathrm{AIC}=538.5 ;$ somatoform syndrome: $z[1147]=-0.50, p=.611$, Nagelkerke $R^{2}=.166, \mathrm{AIC}=$ $539.8)$.

In a second part, where the intention to start psychotherapy was used as an outcome, the only significant interaction (S-Figure $5 \mathrm{C}$ ) could be observed in the female subsample for attachment avoidance on the association between the intention to start psychotherapy and any depressive syndrome $\left(z[3542]=-1.99, p=.047\right.$, Nagelkerke $\left.R^{2}=.191, \mathrm{AIC}=4003.1\right)$. This interaction indicates that female students screened positive for any depressive syndrome would be more likely to intend starting psychotherapy when exhibiting higher attachment avoidance as compared to female students screened positive for any depressive syndrome with lower attachment avoidance. Conversely, these results were not found in the total sample $\left(z[4697]=-1.95, p=.051\right.$, Nagelkerke $R^{2}=.191$, AIC $\left.=5164.1\right)$ nor in the male subsample $\left(z[1147]=-0.11, p=.910\right.$, Nagelkerke $\left.R^{2}=.210, \mathrm{AIC}=1141.9\right)$.

Hayes, A. F. (2013). Introduction to mediation, moderation, and conditional process analysis: A regression-based approach. New York, NY: Guilford Press. 


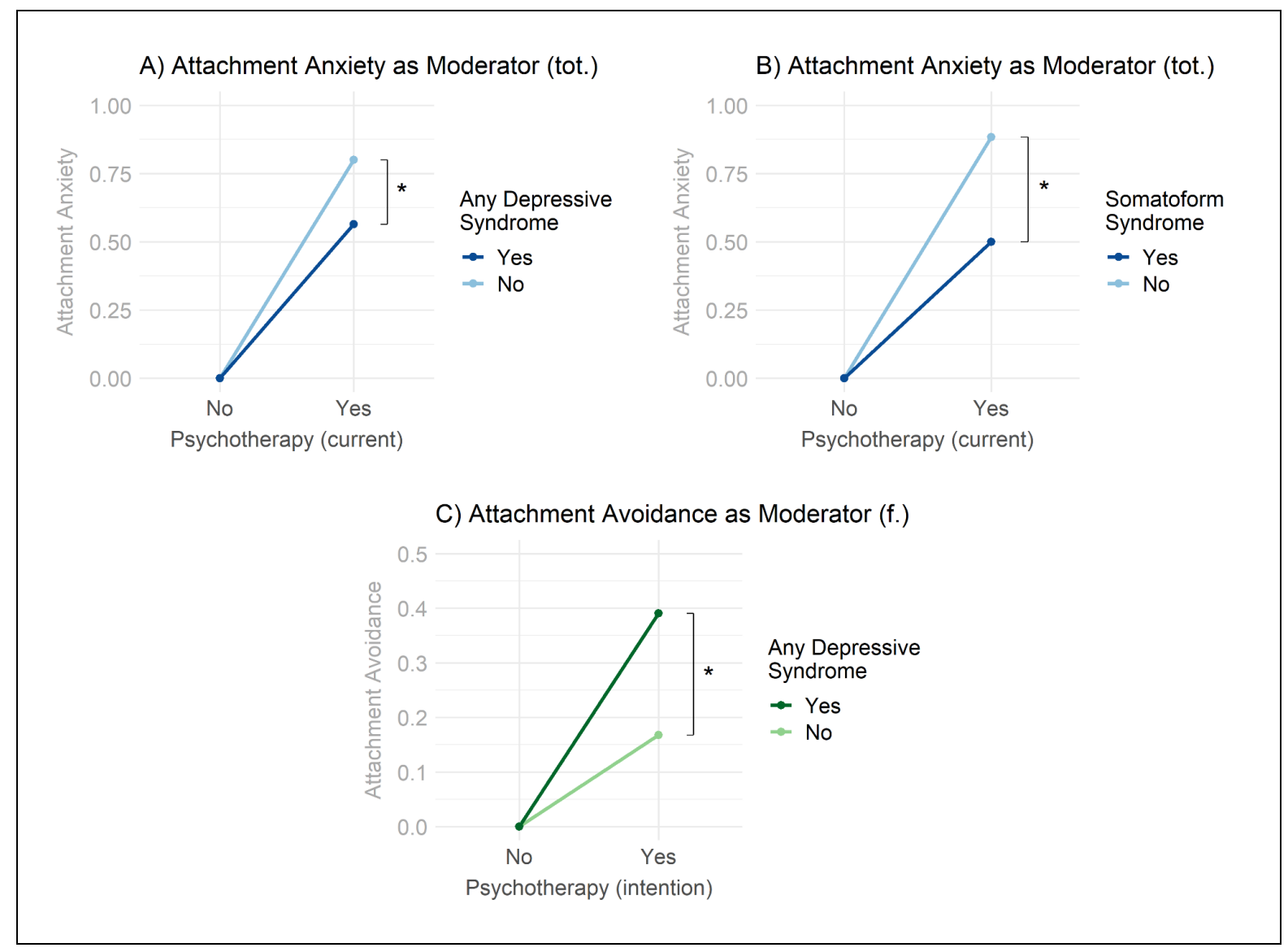

Figure 5. Significant Interactions regarding Attachment Dimensions, Psychiatric Syndromes, and Psychotherapy Use

Note. tot. $=$ total sample, $f$. female subsample, $p$-values were not adjusted for multiple testing. $*=p<.05$ 